\title{
Tailoring Biomaterial Scaffolds for Osteochondral Repair
}

Sandra Camarero-Espinosa ${ }^{\mathrm{a}}$ and Justin Cooper-White ${ }^{\mathrm{a}, \mathrm{b}, \mathrm{c}, *}$

${ }^{a}$ Australian Institute for Bioengineering and Nanotechnology (AIBN), Cnr College Rd \& Cooper Rd, Building 75, Brisbane QLD 4072, Australia.

${ }^{b}$ University of Queensland, School of Chemical Engineering, Brisbane, Qld, Australia.

${ }^{c}$ Commonwealth Scientific \& Industrial Research Organisation (CSIRO), Manufacturing Flagship, Clayton, Vic 3168, Australia.

- e-mail address: j.cooperwhite@uq.edu.au 


\begin{abstract}
Articular cartilage is a mechanically and structurally complex, lubricious tissue that permits load-bearing and frictionless movement of our joints upon articulation. Unfortunately, cartilage is unable to properly self-heal as a result of acute trauma or damage, resulting in many cases in significant pain, reduction in physical activity and quality of life for the patient.. Due to the inability of resident cells to repair damaged osteochondral tissue, researchers have focused on utilizing endogenously or exogenously sourced cells (chondrocytes or tissue-derived mesenchymal stem cells), with or without scaffolds, to encourage the secretion of extracellular matrix (ECM) that replicates this highly anisotropic osteochondral tissue, in which the phenotype of the cells and the composition and orientation of the ECM varies along its depth. Important advances have been achieved towards the development of scaffolds with macroscopically relevant structures, however, articular cartilage and bone tissue contain complex, hierarchical structures that provide cells with biophysical and biochemical cues spanning multiple length scales, presenting researchers with some substantial challenges. This review summarizes the latest advances in mechanical, biochemical and topographical engineering of biomaterials to drive requisite biological responses, such as cell differentiation and matrix deposition, in an effort to achieve functional repair of osteochondral defects.
\end{abstract}

Keywords: tissue engineering, cartilage, osteochondral, surface engineering, biomaterial, scaffold. 


\section{Introduction}

Hyaline cartilage is a stratified, multilayered tissue that anchors to the subchondral bone. Both the phenotype and orientation of cells (chondrocytes) and the composition and architecture of the extra cellular matrix (ECM) varies substantially along the depth of this complex tissue (Figure 1) (Camarero-Espinosa et al., 2016b, a; Temenoff and Mikos, 2000; Williams et al., 2008). It is an avascular tissue of very low cellular density $(\sim 1,000,000$ cells per cubic centimetre), which upon injury, or degeneration due to wear-and-tear, is unable to regenerate or restore full functionality. Furthermore, cartilage is a non-innervated tissue, which favours (due to the lack of pain being felt by the patient) the propagation of any defects from the articular cartilage surface through to the bone by continued loading, leading to thinning of the tissue and remodelling of the bone, or a condition referred to as trauma-induced osteoarthritis (Blanco et al., 1998; Buckwalter, 2002; Furukawa et al., 1980; Vogt and Imhoff, 2006).

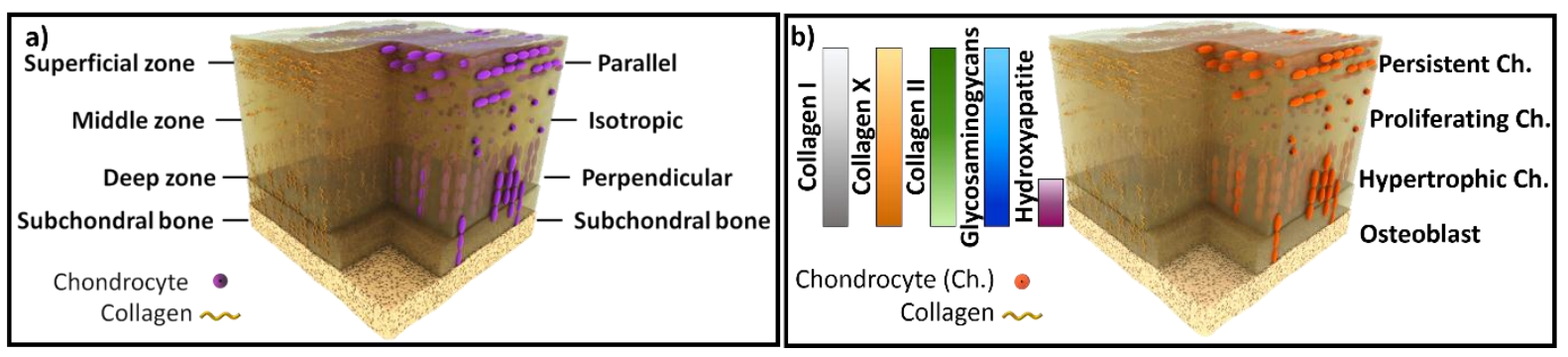

Figure 1. a.) Schematic representation of the stratified structure of hyaline cartilage in which the morphology of chondrocytes and orientation of collagen vary along the depth of the tissue. Reproduced from (Camarero-Espinosa et al., 2016a) with permission from The Royal Society of Chemistry. b.) Schematic representation of the distinct extra cellular matrix composition and chondrogenic phenotype (Ch., chondrocyte) present in articular cartilage. 
There are a number of currently practiced clinical approaches to cartilage tissue regeneration, including those based on the recruitment of endogenous mesenchymal stem cells from subchondral bone, i.e., microfracture; the in-vitro expansion and re-implantation of biopsied autologous chondrocytes, i.e., autologous chondrocyte transplantation; or the transplantation of full osteochondral allografts (Brittberg et al., 1994; Filardo et al., 2014; Hangody and Fules, 2003; Makris et al., 2015; Mithoefer et al., 2009; Smith et al., 2005; Steadman et al., 1998). However, the absence of a support or scaffold capable of guiding cell differentiation and encouraging the secretion of a structurally coherent ECM, coupled with the inherent predisposition of chondrocytes to de-differentiate into fibroblast-like phenotypes upon ex-vivo expansion, represent significant limitations to these current clinical treatments that unfortunately fail in reproducing the structure and, therefore, the mechanical properties of the neotissue (Makris et al., 2015), Clinical approaches usually require long post-operative treatments with limited mechanical loading until tissue remodelling is achieved at the defect site, and although patients initially indicate a significant improvement (mostly due to a reduction in pain), follow-up studies show that the functionality of the tissue is not improved in the long-term (Messner and Gillquist, 1996; Minas and Peterson, 2000; Mithoefer et al., 2009; Steadman et al., 2003).

Tissue engineering strategies aim to combine biomaterial scaffolds and cells to regenerate injured tissue. Due to the presence of a single unique cell type and the avascular character, articular cartilage tissue was predicted over twenty years ago to be one of the first tissues to be successfully engineered (Langer and Vacanti, 1993; Vacanti, 1988; Viola et al., 2003). Bone tissue was similarly expected to relatively simple to replicate in terms of cellular and ECM composition. However, it has proven difficult to replicate the complex architectures of the native individual counterparts, let alone to produce functional, integrated tissue in sites where both of these tissues exist in a near continuum, that is, in osteochondral defect sites (Huey et 
al., 2012). Scaffolds aimed at repairing articular cartilage have in general focused on exploiting hydrogel materials to support or even drive chondrocyte-like phenotypes, due to their high water content and the inherent ability to retain a rounded morphology of the implanted cells (Lau and Wang, 2013; Slaughter et al., 2009; Spiller et al., 2011; Wang et al., 2006). However, hydrogels are macroscopically isotropic materials, and hence they lack of the ability to mimic the complex hierarchical structure of native articular cartilage, driving the development of multi-layered or stratified biomaterial scaffolds that better resemble the multi-zonal structure, mechanical and biochemical properties of articular cartilage (Karpiak et al., 2012; Liverani et al., 2012; Mohan et al., 2011; Nguyen et al., 2011; Vaquette and Cooper-White, 2013). Reinforced hydrogel scaffolds, through the addition of nanofibers, nanoparticles, interpenetrating polymer networks or varying cross-linking densities, have also attempted to address the inherently poor mechanical properties of hydrogels to improve their ability to withstand the loads applied to the joint surface in the knee joint (DeKosky et al., 2010; Jha et al., 2010; Liao et al., 2013; Moutos et al., 2007; Tan et al., 2009; Visser et al., 2015). Scaffolds targeted for applications in repairing full-thickness osteochondral defects have combined diverse types of materials, such as hydrogels or porous sponges (mimicking the 'articular cartilage region'), with porous or fibrous rigid scaffolds (made from polymeric or inorganic ceramic-type materials (or combinations of both)) to mimic the 'bone' region (CamareroEspinosa et al., 2016c; Dormer et al., 2012; Jeon et al., 2014a; Jeon et al., 2014b; Yousefi et al., 2015). However, whilst polymeric (or even composite) materials offer many possibilities to the field of tissue engineering, in terms of controllable chemical composition, tunable mechanical property slates and processability, they inherently lack the plethora of biological cues provided by the native tissue microenvironment, through cell-ECM and cell-cell communication, that facilitate tissue remodeling and repair. 
Cartilage is a hierarchically structured material in which biophysical and biochemical cues are present at molecular and structural levels. The ECM throughout osteochondral tissue, which is itself secreted and modulated by the encapsulated chondrocytes, presents complex gradients of biochemical cues, such as varying concentrations of glycosaminoglycans and glycoproteins within each region of the tissue, or biophysical (topographical and mechanical) cues, such as nano-sized, spatially patterned interactions (with a periodicity of $67 \mathrm{~nm}$ ) provided by mechanically-robust collagen fibers. Cells interact with these stimuli in a spatiotemporal manner, via integrins and other cell-surface receptors, activating biological responses such as cell migration, proliferation, differentiation and apoptosis. Engineering interactions between cells and biomaterial scaffolds (the "interactome") through mimicry of the hierarchical nature of the native ECM is thus potentially of great relevance to eliciting control over the molecular and structural cues capable of determining cell fate decisions and neo-tissue formation to achieve functional osteochondral tissue repair. This review thus focuses on describing the latest advances in tailoring biomaterials to engender or drive biological responses that favor the regeneration of osteochondral tissue.

\section{The complex hierarchical structure of articular cartilage tissue}

The complex architecture throughout the articular cartilage to the subchondral bone interface that constitutes osteochondral tissue spans millimeter (macro)- through to nanometer lengthscales (Stevens and George, 2005; Williams et al., 2008). At the macro-scale, adult articular cartilage is a multi-zonal material in which three layers, accounting for different ECM composition, orientation and cell phenotypes, can be distinguished. This multi-layer 'zonal' organization is developed as a consequence of the hydrodynamic forces applied to the tissue during skeletal development through to maturity, and it has a direct impact on the robust mechanical property slate of the tissue (Cohen et al., 1998). 
From the articulating surface to the subchondral bone, the following zones can be identified: the superficial or tangential zone; the middle or transitional zone; and the deep or radial zone (Figure 1, a). The base of the deep zone displays a tide-mark that represents the start of the calcified area, serving as a transitional zone between the soft cartilaginous tissue and underlying hard bone.

The superficial zone represents $10-20 \%$ of the total thickness of articular cartilage and is characterized by the presence of a densely packed network of thin collagen fibres, that align parallel to the surface, and a minimal concentration of GAGs (Athanasiou et al., 2009). Densely-packed chondrocytes (compared to the rest of the tissue) appear elongated and flattened (Figure 1, a). Chondrocytes of this zone are responsible for the appositional growth of the tissue and are known as 'persistent chondrocytes' (Figure 1, b). The superficial layer is covered by a thin acellular layer (measuring a few hundred nanometers), termed the lamina splendes, which serves as a low-friction surface (Fujioka et al., 2013; Macconaill, 1951; Wu et al., 2008). This protective layer of macromolecules is high in glycoproteins, in particular proteoglycan 4 (PRG4), also known as superficial zone protein (SZP) or lubricin (Flannery et al., 1999; Schumacher et al., 1994). The arrangement of collagens and the relatively low concentration of negatively charged, water-holding glycosaminoglycans (GAGs) confers the superficial zone with the highest permeability (across all zones) and an optimized capability to dissipate shear forces (Chen et al., 2001; Eyre and Wu, 1995; Knudson and Knudson, 2001; Maroudas et al., 1969).

Under the superficial zone resides the middle zone. It accounts for $40-60 \%$ of the total thickness and is characterized by a collagen II and proteoglycan rich ECM (Figure 1, b) (Eyre, 2002; Knudson and Knudson, 2001). Collagen in this layer appears as thick fibres (50-300 nm diameter), arranged in arcades linked together through smaller diameter collagen fibres (Figure 
1, a). Chondrocytes within this zone are rounded and randomly distributed and are denominated as 'proliferating chondrocytes' (Figure 1, b). Due to a higher concentration of GAGs in this zone, the permeability of the tissue is also lower than the superficial zone and supports moderate compressive forces (Chen et al., 2001; Mow et al., 1984; Venn and Maroudas, 1977).

The deep zone of articular cartilage (representing 20-50\% of the total thickness) is characterized by an arrangement of collagen and elongated chondrocytes (hypertrophic) that lie perpendicular to subchondral bone. The concentration of GAGs in this zone reaches the maximum seen within articular cartilage, whilst the cell density is the lowest compared to the superficial and middle zones (Eyre, 2002; Venn and Maroudas, 1977). Collagen X and collagen I are also present in this zone in small amounts (Eyre and Wu, 1995). The deep zone has very low permeability, with practically no fluid flow permitted through the tissue. This zone withstands the highest interfacial shear forces (Macconaill, 1951; Mow et al., 1984). The base of the deep zone presents a calcified zone that can be identified by the presence of the tidemark (Redler et al., 1975). The calcified area, rich in apatite and alkaline phosphatase (Figure 1, b) and poor in chondrocyte number, serves as an interface between the soft cartilage and hard subchondral bone and supports a gradient in mechanical properties between these two tissues. During development, in the calcified area, hypertrophic chondrocytes from the deep zone direct the mineralization of the surrounding matrix and undergo apoptosis, leaving behind a cartilaginous scaffold that serves as template for osteoclast invasion and bone growth (Hoemann et al., 2012; Kronenberg, 2003). This lowest region of the deep zone is composed of small diameter collagen fibril bundles $(10-20 \mathrm{~nm})$ and a high concentration of osteoblastsecreted vesicles that are thought to deliver high concentrations of ions to the mineralization front (Anderson et al., 2005). 
Below the deep zone is the subchondral bone plate. Subchondral bone is a nanocomposite material composed of glycoproteins, such as collagen, laminin and fibronectin, and hydroxyapatite (HA). This hybrid composite contains a range of features that are nano-sized, such as the HA crystals ranging in length from 20-80nm and thickness of 2-5nm (Olszta et al., 2007). Underneath the subchondral bone plate, the subchondral trabecular bone, accounts for a spongy-like structure that is highly vascularized. Trabecular bone is a cellular solid with an interconnected porous structure. The pores are of diameters of order $\sim 1 \mathrm{~mm}$ and walls (trabeculae) of a few micrometres in thickness. The pores appear aligned in the direction of the applied load and are filled with numerous cell types, ECM and vasculature (the bone marrow). This anisotropy in the porous structure is responsible for the observed anisotropic mechanical properties of trabecular bone.

At the cellular-scale, chondrocytes in adult articular cartilage are well separated from each other, accounting only for $1-5 \%$ of the total volume of the tissue, and they are surrounded by an organised radially-variant microenvironment, termed the chondron (Poole, 1997). The chondron is produced as a result of the proteins and glycosaminoglycans (GAGs) synthesized and secreted by the cells assembling into larger structures as they diffuse away from the cell, defining multiple biochemical and biophysical cues to the cells. Spatially, chondrocytes are firstly surrounded by a glycocalyx (glycan-rich cell surface-bound matrix) and further by the pericellular capsule, forming together the pericellular matrix. The pericellular matrix is characterized by a high content of aggrecan, link protein and hyaluronan (Poole et al., 1982). Aggrecan-hyaluronan assemblies which can form are not present and these molecules appear dissociated. The collagen content differs from the bulk extracellular matrix composition having higher concentrations of collagen IX and VI (Eyre, 1991; Youn et al., 2006). Collagen II fibres are not present in this region, appearing as thin fibrils of 10-15 nm diameter that interconnect, forming a tight woven structure (Poole et al., 1982). These nanometer-sized collagen fibres 
interact directly with the chondrocytes, serving as hydrodynamic protection from the applied mechanical loads (Poole, 1997; Poole et al., 1987). The pericellular matrix transitions into the territorial matrix and the inter-territorial matrix, commonly referred to as extracellular matrix. In the territorial matrix, small collagen fibrils assemble into bundles that further arrange into larger fibres of 50-300 nm diameter in the inter-territorial matrix or ECM (Eyre, 1991). The territorial matrix is also higher in concentration of proteoglycans, in particular being rich in chondroitin sulfate (Hunziker et al., 1997).

The microenvironment surrounding and supporting cells in articular cartilage and interfacial tissues (such as the osteochondral interface) is critical for the development and homeostasis of the tissue, allowing cells (through their surface receptors) to respond to signalling (both freely diffusing and bound) molecules, as well as the mechanical properties and topographical features of the ECM, such as the varying diameters of collagen fibres present in cartilage in different regions. Defining upfront the composition, structural organisation, pertinent lengthscales and function of the cellular microenvironment within each layer of this complex tissue (as we have done in the above text) is thus the first step to recapitulating the requisite cues that induce desired cellular responses during repair of damaged tissue. The second step is developing methods by which to present these cues in a controlled manner through tailoring biomaterials to interact with endogenously derived or exogenously provided cells and direct their fate choices. We will now detail recent progress in the field aimed at developing such material systems for tissue engineering osteochondral tissue.

\section{Tailoring biofunctionality into materials for osteochondral tissue regeneration}

Mature articular cartilage has an inherent inability to repair itself post damage, however, regeneration of far more complex tissues and organs, such as cardiac muscle, liver or lung 
tissue, can be achieved from pluripotent stem cell starting points (or in some cases resident tissue stem cells) by recapitulating the developmental stages and processes observed during organogenesis of these tissues (Burridge et al., 2012; Coraux et al., 2005; Duncan et al., 2009; Laflamme and Murry, 2011; Ott et al., 2010; Takebe et al., 2013). Recapitulating the developmental events resulting in the creation of the osteochondral interface in joints is thus a reasonable starting point in devising methods and materials to achieving tissue engineering of osteochondral tissue defects. Through the implementation of the essential spatiotemporal signals that reproduce developmental events, such as the condensation/aggregation of bonemarrow derived mesenchymal stem cells, and the addition of soluble morphogens known to be present during tissue specification in the joint and the differentiation of these cells into chondroprogenitors, one may achieve the generation of immature cartilage. However, the cartilage tissue will be isotropic, non-hierarchical and mechanically weaker than native tissue. Such an approach does not provide any structural or mechanical cues present in the ECM, nor the periodicity and scale at which these signals appear in the native microenvironment surrounding the cells.

Many studies have thus focussed their attention on the use of decellularized, naturally derived scaffolds, or scaffolds fabricated from purified or synthetically produced proteins constituting cartilage ECM (or combinations thereof), under the assumption that the recognition of cells to this biochemical microenvironment would be sufficient to induce cell adhesion, migration and differentiation. One of the first U.S. Food and Drug Administration approved treatments of osteochondral defects involving the use of biologically-derived materials was the use of collagen flaps as a support matrix for autologous chondrocyte transplantation, or for attachment and differentiation during microfracture procedures. However, studies of the long-term outcome of these clinical treatments showed that there is limited improvement in the functionality of the tissue, pointing to the need of more sophisticated materials capable of 
orchestrating the development and homeostasis of cartilaginous tissue, from either endogenously-derived cells (MSCs or chondrocytes) or allogeneic cell sources (Moseley et al., 2010; Niemeyer et al., 2014).

Engineering biofunctionality into synthetic materials has for some time been pursued as a promising alternative to current clinical treatments. The processability of synthetic polymeric biomaterials, when coupled with the latest advances in nanotechnology, have enabled an explosion of novel materials capable of evoking desired biological responses in cells, controlling their adhesion, migration and differentiation via integrin coupling and activation of critical fate determining signalling pathways, such as those regulated by Rac and Rho, protein kinase $\mathrm{C}$ and MAP kinase (Humphries et al., 2006; Prowse et al., 2011). Tailoring biomaterials for enhanced biofunctionality can be achieved using a variety of approaches that involve the introduction of chemical, topographical or mechanical cues via top-down or bottom-up approaches (Figure 2).

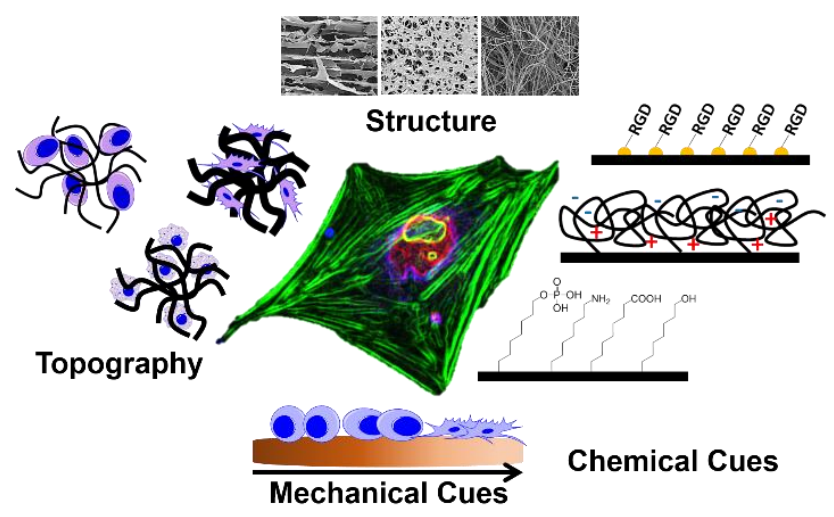


Figure 2. Schematic representation of common chemical, topological, mechanical and structural cues used to evoke biological responses on cells.

\subsection{Mimicking ECM proteins, proteoglycans and cell adhesion molecules in osteochondral tissue through chemical functionalization}

Surface or bulk chemical modification is often exploited to tune cellular responses to biomaterials, ranging from influencing biocompatibility through to controlling cell fate decisions (adhesion, migration, proliferation, differentiation, apoptosis (programmed death)). A broad range of physical and chemical techniques have been utilized, with the most commonly utilized techniques being absorption, self-assembly, grafting, stamping, and layer-by-layer deposition (Khademhosseini et al., 2006; Shin et al., 2003). In terms of eliciting fate control, biochemical functionalization of culture substrates or scaffolds aims to mimic the dynamic macromolecular state of the native tissue microenvironment surrounding and supporting cells, and are traditionally based on the introduction of bioactive moieties that encourage or mimic cell-ECM or cell-cell interactions (through integrins and cell adhesion molecules), or activate transmembrane receptors at cell surfaces that convert an extracellular signal to an intracellular signal. This biofunctionalisation has been achieved traditionally using either tissue-derived (extracted) ECM proteins (such as collagen, fibronectin and laminin) or soluble factors (including cytokines such as growth, maintenance and differentiation factors), but more recently using synthesised matrix molecules or fragments/mimics thereof (including recombinant proteins, protein fragments, peptide sequences or synthetic small molecules). Such bioactivity can be introduced into polymeric surfaces or scaffold materials by chemical coupling to the polymer backbone or pendent end chains, or by engendering 'delivery' into the polymer matrix, by the incorporation of stimuli-responsive nanoparticles or cleavable chemical bonds. 


\subsubsection{Peptides}

Engineering functionality into polymers using peptide sequences, via chemical bonding or selfassembly, to activate desired biological responses has a proven track record in biomaterials and tissue engineering (Lebaron and Athanasiou, 2000; Stevens and George, 2005). Controlled surface presentation of peptide sequences thus offers the potential to study direct ECM-cell and cell-cell interactions and eventually, exploit this interactions to induce cell differentiation and osteochondral tissue repair in 3-dimensional (3-D) systems (Sreejalekshmi and Nair, 2011).

Cell adhesion to synthetic biomaterial surfaces or scaffolds is the initial requisite event to any tissue engineering strategy. For this reason, many researchers first focus their attention on peptide sequences that are representative of known adhesion sequences in ECM proteins recognized by cell surface integrins (Table 1). These peptide sequences can easily be introduced into biomaterials by Huisgen azide-alkyne cycloaddition, Michael-type addition reactions or via host-guest interactions (Boateng et al., 2005; Kim and Park, 2006; Li and Cooper-White, 2014; Li et al., 2014; Sreejalekshmi and Nair, 2011). Self-assembled monolayers (SAMs), consisting of amphiphilic molecules containing head groups (commonly alkylsilanes) that form stable interactions with a rigid substrate and an alkyl tail that can be functionalized with a great variety of functional groups, can also be utilised to present peptides and study their interactions with cell surface receptors (Biesalski et al., 2006; Moore et al., 2011; Mrksich, 2009).

The choice of the peptide adhesion sequence is however important, as they determine the integrin cohort engaged during the adhesion event, which in turn effects different signal pathway activation, cytoskeletal stress development and morphology. Peptide-based adhesion motifs, such as Arg-Gly-Asp (RGD), Ile-Lys-Val-Ala-Val (IKVAV) and Tyr-Ile-Gly-Ser-Arg 
(YIGSR), present in extracellular matrix proteins fibronectin and laminin, have seen significant investigation in recent years, and their use in biomaterial engineering has produced important insights into cell motility, adhesion, proliferation and differentiation (Lebaron and Athanasiou, 2000; Rahmany and Van Dyke, 2013). In terms of cartilage generation, there have been numerous reports of the benefits of these commonly utilised peptides (in particular RGD), although temporal control over their presentation is clearly important. For example, Connelly et al. showed that adhesion via RGD peptide of MSCs can promote chondrogenic differentiation, but only when presented in a time-dependant manner - if the RGD motif is persistent, chondrogenic differentiation of MSCs is inhibited (Connelly et al., 2007). However, Salinas and Anseth have shown that when RGD motifs were presented via matrix metallopeptidase-13 (MMP-13) cleavable linkers in a poly(ethylene oxide)-based hydrogel scaffold, the differentiation of hMSCs towards chondrogenic phenotypes is favoured, as was demonstrated by an increased GAG and collagen type II deposition (Salinas and Anseth, 2008). It is well established that chondrocytes require the maintenance of a rounded morphology to keep their phenotypic state, with de-differentiation into a fibroblastic phenotype occurring rapidly when these cells adopt a highly spread, flattened morphology (Benya and Shaffer, 1982; Holtzer et al., 1960; Tan et al., 2011), possibly providing reasoning as to why only a temporary presence of the RGD adhesion motif is required if chondrogenesis is to be supported, so that significant cell spreading and cytoskeletal tension is not.

Taking a more comprehensive approach, researchers have also focused on assessing potency of other peptide sequences that mimic functions of the actual molecules present in cartilaginous and ossified ECM. Collagens (of varying types) represent a main component of both bone and cartilage ECM, and peptide sequences derived from various collagens have been used successfully to induce osteogenic or chondrogenic differentiation. The amino acid sequence GFOGER (Table 1) was first identified by Knight et al. (Knight et al., 2000) as the recognition 
site, in triple-helix native collagens I, II and III by $\alpha 1 \beta 1$ and $\alpha 2 \beta 1$ integrin subunits and it has been successfully exploited as a cell adhesion peptide or chondrogenic inducer in a number of biomaterial systems (Connelly et al., 2011; Mhanna et al., 2014; Raynor et al., 2007). Most recently, the GFOGER sequence has been incorporated into degradable poly(ethylene oxide) hydrogels, confirming its ability to support chondrogenic differentiation of hMSCs, with increased expression and deposition of collagen II and GAGs after 21 days of culture in FGF2 supplemented maintenance media, as compared to peptide-free hydrogels (Mhanna et al., 2014). A peptide sequence within Type I collagen, DGEA, was identified as an $\alpha 2 \beta 1$ integrin subunit recognition site, and has been shown to regulate osteogenic differentiation of hMSCs (Carvalho et al., 2003; Staatz et al., 1991). In a study by Hennessy et al., HA discs were coated with different collagen-mimetic peptides, i.e. DGEA, GTPGPQGIAGQRGVV (P15) and GFOGER, to increase adhesion of hMSCs. Hennessy et al. measured greater cell adhesion and spreading on P15- and DGEA-coated discs as compared to the native HA, in the absence of serum proteins (Figure 3). When the surface of the peptide-coated HA discs was incubated in the presence of serum proteins, creating an overcoating, cell adhesion was comparable to naive HA discs. However, DGEA-coated HA disks showed enhanced expression of common osteogenic markers, such as osteocalcin and alkaline phosphatase activity in comparison to the pristine HA in-vitro, after 2 weeks of culture in the presence and absence of induction media, and enhanced bone formation in-vivo in Sprague-Dawley rats tibia defect models after 5 days of implantation (Hennessy et al., 2009). Other peptide sequences derived from naturally occurring proteoglycans or growth factors that bind GAGs in the ECM of cartilage and bone tissue, such as the collagen I binding domain in the core protein of decorin (KLER) or the heparin sulfate binding domain of fibroblast growth factor-2 (YKRSR and KRTGQYKLGSKTGPGQK) have also been used to drive chondrogenic and osteogenic differentiation of hMSCs, respectively (Table 1) (Lee et al., 2007; Salinas and Anseth, 2009). 
Table 1. Peptide sequences relevant to tissue engineering of osteochondral defects

\begin{tabular}{|c|c|c|c|c|}
\hline Peptide function & Binding sequence & Protein/GAG source & Cell-response & Reference \\
\hline $\begin{array}{l}\text { Cell-ECM } \\
\text { interactions }\end{array}$ & RGD & Multiple ECM proteins & $\begin{array}{l}\text { Chondrogenesis } \\
\text { (time- } \\
\text { dependent); } \\
\text { Osteogenesis. }\end{array}$ & $\begin{array}{l}\text { (Connelly et al., } \\
\text { 2007; Frith et al., } \\
\text { 2012b; Salinas and } \\
\text { Anseth, 2008) }\end{array}$ \\
\hline $\begin{array}{l}\text { Cell-ECM } \\
\text { interactions }\end{array}$ & IKVAV & Laminin & Osteogenesis & (Frith et al., 2012b) \\
\hline $\begin{array}{l}\text { Cell-ECM } \\
\text { interactions }\end{array}$ & GFOGER & Collagen I, II and III & Chondrogenesis & $\begin{array}{l}\text { (Connelly et al., } \\
\text { 2011; Mhanna et } \\
\text { al., 2014; Raynor } \\
\text { et al., 2007) }\end{array}$ \\
\hline $\begin{array}{l}\text { Cell-ECM } \\
\text { interactions }\end{array}$ & DGEA & Collagen I & Osteogenesis & $\begin{array}{l}\text { (Carvalho et al., } \\
\text { 2003; Hennessy et } \\
\text { al., 2009; Staatz et } \\
\text { al., 1991) }\end{array}$ \\
\hline $\begin{array}{l}\text { Cell-ECM } \\
\text { interactions }\end{array}$ & YKRSR & Heparin & Chondrogenesis & (Lee et al., 2007) \\
\hline $\begin{array}{l}\text { Cell-ECM } \\
\text { interactions }\end{array}$ & $\begin{array}{l}\text { KRTGQYKLGSK } \\
\text { TGPGQK }\end{array}$ & $\begin{array}{l}\text { Heparin binding } \\
\text { domain of FGF-2 }\end{array}$ & Chondrogenesis & (Lee et al., 2007) \\
\hline $\begin{array}{l}\text { Cell-ECM } \\
\text { interactions }\end{array}$ & KLER & $\begin{array}{l}\text { Collagen I binding } \\
\text { domain of decorin }\end{array}$ & Osteogenesis & $\begin{array}{l}\text { (Salinas and } \\
\text { Anseth, 2009) }\end{array}$ \\
\hline $\begin{array}{l}\text { Cell-cell } \\
\text { interactions }\end{array}$ & Ac-HAVDIGGGC & N-Cadherin & Chondrogenesis, & (Bian et al., 2013) \\
\hline
\end{tabular}

Cell adhesion molecules enable cell-cell interaction via formation of adherens junctions and modulation of cell signalling processes during MSC condensation and chondro- and osteogenic differentiation in developmental stages. Peptide sequences derived from cadherins have also been proven recently to support the induction of differentiation of hMSCs to both osteogenic and chondrogenic lineages (Alimperti and Andreadis, 2015). N-cadherin orchestrates early chondrogenic differentiation of MSCs and when the known complementary binding sequence 
in its outermost extracellular domain (Ac-HAVDIGGGC) was incorporated into a hyaluronic acid-based hydrogel scaffold, it was shown to promote the differentiation of MSCs both, invitro and in-vivo (Bian et al., 2013).
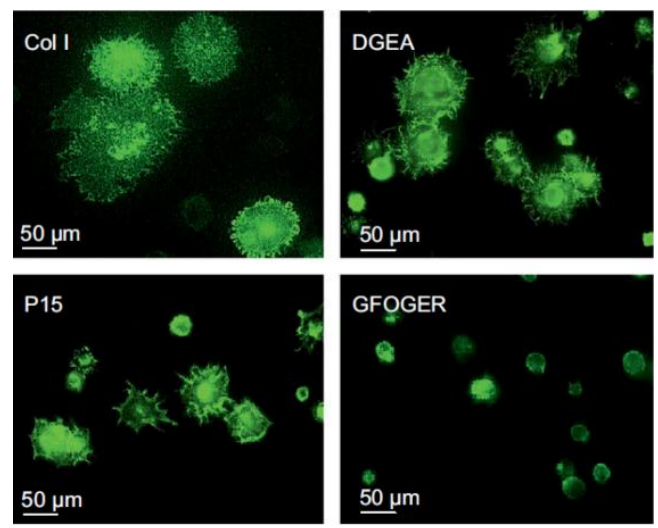

Figure 3. hMSCs after $1 \mathrm{~h}$ cultured on hydroxyapatite substrates coated with collagen I or collagen derived peptide sequences DGEA, P15 (GTPGPQIAGQAGVV) and GFOGER. Cells cultured on collagen I, P15 and DGEA, showed an increased spread area while cells cultured on GFOGER coated surfaces showed a decreased spread area. Cells were labelled with Alexa-488 Phalloidin. Reprinted from Biomaterials, 30 (10), Hennessy, K. M.; Pollot, B. E.; Clem, W. C.; Phipps, M. C.; Sawyer, A. A.; Culpepper, B. K.; Bellis, S. L., The effect of collagen I mimetic peptides on mesenchymal stem cell adhesion and differentiation, and on bone formation at hydroxyapatite surfaces. (C) (2009), with permission from Elsevier.

Whilst a multitude of approaches can be utilised to bind peptides to polymer backbones or pendant groups or to SAMs, it has also become clear that the manner by which they are presented to cells is also important. Cooper-White and co-workers developed a versatile biomaterial platform for controlled peptide presentation based on a phase-separating block copolymer functionalised with peptides using many of the aforementioned chemistries (Frith et al., 2012a; Frith et al., 2012b; Li and Cooper-White, 2014; Li et al., 2014). Investigations into human mesenchymal stem cell responses to these functionalised biomaterials (in 2D and 3D formats) showed that, when parameters such as the type, density and lateral spacing of ligand presentation are controlled at the nanometer scale, biological responses such as the 
formation and maturation of focal adhesions, migration, cell shape and size, and directed differentiation towards specific tissue lineages (osteogenic, adipogenic) can also be controlled (Frith et al., 2012a; Frith et al., 2012b; George et al., 2010; Li and Cooper-White, 2014; Li et al., 2014). This same system has most recently been used to assess the relative impact of different peptide sequences (spanning those listed in Table 1) on supporting chondrogenic and osteogenic differentiation of hMSCs, confirming that peptide type, ratio and spatial presentation are important parameters for optimal conversion to these tissue cell endpoints (Camarero-Espinosa and Cooper-White, 2016). Although SAMs do not allow the formation of defined nanopatterns or explicit spatial control over the chemical composition of the monolayer, they can be combined with other nanotechnologies such as polymer-assisted nanopatterning of gold nanoparticles or dip-pen nanolithography to achieve such control over peptide presentation, but only in 2D (Salazar et al., 2006).

\subsubsection{Self-assembled peptide scaffolds}

A viable alternative to binding peptides on polymer backbones or pendant groups in order to present them throughout 3D space (in solid or hydrogel scaffolds for example), is to make the 3D scaffold from peptides that inherently self-assemble into 3D structures. Peptide selfassembly is the formation of ordered supramolecular architectures via weak interactions such as Van der Waals, electrostatic or hydrophobic/hydrophilic interactions, leading to the formation of nanopatterned peptide-based materials. Amphiphilic peptides are designed to have a hydrophilic region and an aliphatic region, encouraging self-organization into cylindrical, micellar, $\beta$-sheets nanofibers or monolayers or bilayers (Arslan et al., 2016; Habibi et al., 2016; Zhang, 2003). Since Kisiday et al. (Kisiday et al., 2002) reported on the encapsulation of chondrocytes on hydrogel scaffolds fabricated via self-assembled peptide nanofibers, and the consequent phenotype retention and deposition of a cartilage-like ECM, 
several studies have exploited these materials for the presentation of various biochemical cues capable of driving chondrogenic differentiation of different stem cells. Shah et al. (Shah et al., 2010) reported on the formation of hydrogels based on self-assembled nanofibers displaying a high density of transforming growth factor $\beta-1$ (TGF $\beta-1)$ binding peptides. These hydrogels slowed down the release of the growth factor, as compared to the pristine counterparts loaded with equal amounts of TGF $\beta-1$, and promoted chondrogenic differentiation of hMSCs. These materials showed, after 12 weeks of implantation on a rabbit chondral defect treated with microfracture, the potential to induce the formation of GAG and collagen II rich cartilaginous tissue. Similar hydrogel systems based on self-assembled peptide nanofibers have been used, profiting of the controlled structure and chemical surface presentation, to study the effect of different parameters such as electrostatic character and the presentation of small functional groups, showing an enhancement in chondrogenic differentiation of cells in negatively charged and hydroxyl or phosphate group containing substrates (Benoit et al., 2008; Jayawarna et al., 2009; Sinthuvanich et al., 2012; Ustun et al., 2013). These materials provide a new platform for exploitation in tissue engineering, however to date the majority of them degrade in short periods of time (days to weeks) and they are mechanically very soft materials, and hence their utility in osteochondral tissue engineering remains to be seen.

\subsubsection{Nanofibers and nanoparticles as delivery vehicles of}

\section{biochemical signals}

Nanoparticles and nanofibers have been largely exploited as delivery systems in the pharmaceutical industry (Kumari et al., 2010; Petros and DeSimone, 2010). Tissue engineering has profited from the development of such nanosized biodegradable carriers and incorporated them in biomaterial scaffolds for the introduction of small bio-functional groups or the delivery 
of molecules such as growth factors (Amler et al., 2014; Ji et al., 2011; Jiang et al., 2014; Lee et al., 2011).

The TGF- $\beta$ cytokine superfamily is commonly used on the chondrogenic differentiation of MSCs and plays an important role in biological functions such as proliferation, differentiation and apoptosis (Johnstone et al., 1998). Park et al. (Park et al., 2009) developed a polymeric TGF- $\beta 3 /$ heparin coated microsphere system loaded with dexamethasone and showed a continuous 30 day release profile of both molecules. These nanoparticles showed improved cartilage matrix deposition and lower inflammatory response when implanted in nude mice.

Jung et al. (Jung et al., 2009) prepared polymeric nanoparticles that were coated with TGF- $\beta 1$ trapped heparin and infused them, after mixing with fibrin, into a 3D poly(lactide-cocaprolactone) porous scaffold. These scaffolds were first seeded with human adipose-tissue derived stem cells (hASCs) and then implanted into nude mice where the growth factor was released by diffusion over a period of 5 weeks, showing improved cartilage matrix deposition.

Recently, Man et al.(Man et al., 2014) prepared a dual-delivery system based on coaxially electrospun scaffolds. These nanofibers contained a soft core in which the growth factor TGF$\beta 1$ was trapped, while the stiffer hydrophobic shell was functionalized with covalently attached MSC E7 affinity peptide (EPLQLKM), facilitating initial cell attachment. hMSCs cultured for 14 days on these scaffolds showed improved GAG and collagen II deposition as compared to scaffolds containing only one of these biomolecules.

Exploiting the capability of E7 peptide in recruiting MSCs, Meng et al.(Meng et al., 2015) fabricated composite scaffolds combining the advantage of hydrogels (driving a rounded cell morphology) with demineralized bone particles bearing the E7 peptide. They covalently attached E7 peptide via SMCC (sulfosuccinimidyl 4-(N-maleimidomethyl)cyclohexane-1carboxylate) coupling between an amine group on the demineralized bone particles and the 
terminal thiol group on the peptide and embed them within a chitosan hydrogel. They reported higher survival and proliferation rates of rat bone marrow-derived MSCs after 21 days of culture in-vitro (in induction media) and in-vivo (subcutaneously in nude mice), and higher expression of chondrogenic markers such as aggrecan and collagen II, as compared to a neat chitosan hydrogel or chitosan/decellularized bone particle groups. However, these scaffolds displayed very poor mechanical properties, with an elastic modulus of $\sim 6 \mathrm{kPa}$, and an isotropic structure characteristic of immature cartilage.

Fibrous ECM-mimicking nanofibers and cell-particle encapsulation techniques have been combined to prepare nanofibrous hollow microspheres as injectable chondrocyte carriers (Figure 4) (Liu et al., 2011). These microspheres allowed for the migration of the cells to the core while retaining a rounded shape. After 8 weeks of subcutaneous injection of chondrocyteloaded microspheres, the deposition of GAGs and collagen II was evidenced by immunohistochemistry as compared to the most commonly used poly (ethylene oxide) hydrogels.

Whilst some of these systems provide an interesting platform for time-dependant chondrogenic stimulation, articular cartilage tissue engineering will require better spatial and structural control to enable and actively encourage the formation of a multilayer, matrix and cell phenotype specific tissue.

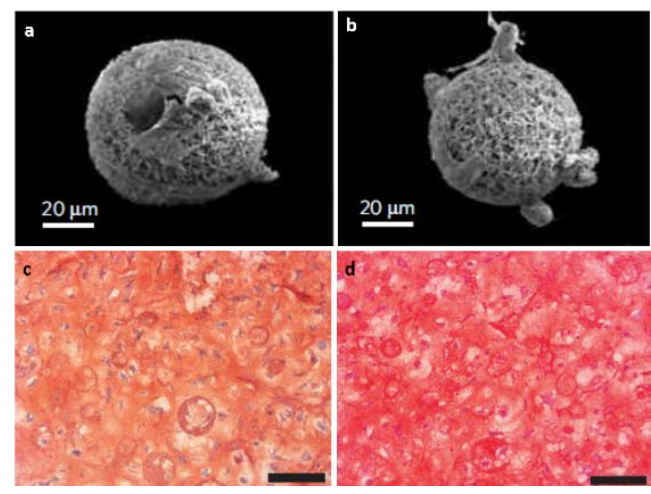


Figure 4. Hollow fibrous microspheres fabricated from star-shaped poly(L-lactic acid) showing some chondrocytes migrated inside (a) and microspheres with 3D morphology chondrocytes growing on the surface (b). Safranin-O (c) and immunohistochemical (d) stains showing the deposition of a GAG and collagen II rich matrix from chondrocytes cultured in-vitro within the microspheres for 3 weeks. Scale bares are $100 \mu \mathrm{m}$. Reprinted by permission from Macmillan Publishers Ltd: Nature Materials (Liu et al., 2011), ( 2011.

In the last decade, the use of rod-shaped cellulose nanocrystals (CNCs) for the reinforcement of polymeric materials has seen some significant investigation, spanning also to their possible applications in tissue engineering scaffolds (Capadona et al., 2008; Jorfi and Foster, 2015). These non-toxic, isotropic, high aspect ratio nanoparticles can be functionalized and oriented to guide the differentiation of cells (Dugan et al., 2013; Dugan et al., 2010). Functionalization of CNCs with labile bonds allows for the controlled release of small molecules, and functionalization with small groups, peptide sequences or amino acids allows for the in-situ formation of hydroxyapatite or control over cell adhesion (Bodin et al., 2007; Camarero Espinosa et al., 2013; Kalaskar et al., 2008; Kuhnt et al., 2015).

Overall, the use of nanoparticles and nanofibers or spatially controlled platforms for the presentation of biochemical cues has produced some important insights for enabling tissue engineering of osteochondral defects. However, the extrapolation of these to 3-D systems in a spatially controlled manner, and furthermore, the combination with additional cues that mimic the nano-, micro-, and macrostructure and the mechanical properties of the native tissue, remains an outstanding challenge.

\section{Mimicking topographical features of the hierarchical osteochondral ECM.}


Chondrocytes are surrounded by a complex milieu of proteins, glycoproteins, proteoglycans and GAGs that provide a variety of topographical cues that vary throughout each of the zonal layers of osteochondral tissue. For example, collagen type II fibre orientation vary in each zone, along with variations in fibre diameter with increasing distance from each individual cell, following the radial arrangement of the chondron (See Section 2). Cells are capable of 'feeling' topographical features from the micro through to nano length-scale, which in turn can affect changes in their shape, size and morphology. Alterations of mesenchymal stem cell shape has been shown to have a determinant influence on their commitment to differentiate into specific tissue cell lineages, as mentioned in Section 3.1.1 This process has been suggested to be regulated predominantly by various interrelated RhoGTPase pathways, that define the resulting F-actin architecture and the development of cytoskeletal tension within a cell (Arnsdorf et al., 2009; Mathieu and Loboa, 2012; Yourek et al., 2007). Engineering biomaterial surfaces and scaffolds that can mimic topographical features present in the native micro- through to macroenvironment of chondrocytes would thus appear to be a relevant pursuit. Numerous techniques exist that permit the surface engineering of nanometer to micrometer sized topographical features on biomaterial surfaces include photolithography and electron beam deposition. Other techniques such as electrospinning allow for the fabrication of 3D-scaffolds or membranes composed of fibres of cross-sections of 10's to 100's of nanometer. (Elsayed and Merkel, 2014; Yaetal., 2013)

Similar to chemical modification, topographical features also affect, initially, the attachment of MSCs through their impact on the size and spacing the focal adhesions (Geiger et al., 2009). Well known surface parameters such as roughness (applied normally to isotropic substrates) or feature size and lateral spacing have been shown to have a direct impact on cell adhesion (Diener et al., 2005). Yim et al.(Yim et al., 2010) showed that MSCs cultured on $350 \mathrm{~nm}$ with gratings of polystyrene (tissue culture plates) and polydimethylsiloxane (PDMS) showed a 
decreased expression of integrin subunits $\alpha 2, \alpha 6, \alpha \mathrm{V}, \beta 2, \beta 3$ and $\beta 4$. They also showed lower stress fibre and focal adhesion densities, along with the cell having a lower stiffness in cells cultured on soft PDMS as compared with those cultured on stiff polystyrene substrates, independently of the grating (as measured by atomic force microscopy (AFM) indentation tests).

After the initial adhesion to the substrate, MSCs arrange their cytoskeleton and thus their structural conformation adapting to the topographical features. In a very comprehensive comparative study on the capability of different patterns to promote chondrogenic differentiation, Wu et al.(Wu et al., 2014) showed the preferential arrangement of cytoskeletal structure, cell aggregation and differentiation of MSCs when cultured in either nano-holes (225 $\mathrm{nm})$, nano-pillars $(250 \mathrm{~nm})$ or nano-grills $(250 \mathrm{~nm})$. MSCs adopted, after $48 \mathrm{~h}$ of culture, a round morphology (suggesting a chondrogenic induction event) on the nano-pillars, while on the nano-holes, the morphology was polygonal, and it was spindle-like on the nano-grills or non-patterned surfaces (Figure 5, a). After 3 days of culture, the morphology of the cells remained unchanged in all the different patterns except on the nano-hole topography, where cells rearranged to a more rounded morphology (Figure 5, b). These morphological observations correlated well with the organisation of F-actin, which was fibrous on the nonpatterned and nano-grilled surfaces, and clustered and cortical on cells cultured on the nanoholes or nano-pillars. It is well known that the state of F-actin organization in MSCs is determinant of the measured stiffness of cells, and this study supported this correlation. The stiffness of the cells after 1 day of culture on the nano-pillars increased by 1.8-fold compared to that of cells on the grills or non-patterned surfaces. However, MSCs cultured on the nanoholes only reached similar values of stiffness ( $750 \mathrm{~Pa})$ only after 3 days of culture. Analysis of matrix protein deposition and gene expression of collagen II on nano-holes and nano-pillars showed a 3- and 5-fold increase, respectively, relative to the non-patterned and nano-grills. A 
similar trend was observed in the gene expression of chondrogenic markers, such as aggrecan and collagen X. Moreover, a decreased expression of collagen I and PRG4 was detected on nano-holes and nano-pillars in comparison to cells cultured on the nano-grills. This study showed a clear impact of surface topography on chondrogenic commitment in MSCs.

However, consistency in topographical-driven outcomes remains elusive, as Prittinen et al.(Prittinen et al., 2014) have shown recently that patterned surfaces displaying micro-pillars (20 $\mu \mathrm{m}$ in diam.) evoke an opposite effect in terms of supporting chondrogenic phenotypes, instead encouraging de-differentiation of primary chondrocytes, as shown by an increased expression of collagen I and decreased expression collagen II, $\mathrm{X}$ and Sox9, to a more fibroblastic phenotype.

The spacing between patterns also appears to play a role in driving certain cell behaviours. Joergensen et al.(Joergensen et al., 2015) prepared 10 different surface micropatterns and 16 combinations of these patterns were used to study human chondrocyte proliferation rates at different passages (P1 and P2). They showed that a micro-pillar diameter of $2.4 \mu \mathrm{m}$ and a spacing $1 \mu \mathrm{m}$ (at a constant pillar height of $1.6 \mu \mathrm{m}$ ) increased chondrocyte proliferation at $\mathrm{P} 2$, compared to all other micropatterns and chondrocytes at P1, which they showed was correlated with the observed increase in cell spread area.

Whilst inducing chondrogenesis solely via topographical features in 2D proves to be difficult due to the inherent tendency of cells to attach and spread, topography-induced osteogenic commitment of stem cells seem to be more consistent. Dalby et al.(Dalby et al., 2007) fabricated, by electron beam lithography, polymethylmethacrylate substrates with ordered and disordered nanoparttterns and studied the effect of these topographical variations on the differentiation of osteoprogenitors and MSCs in absence of osteogenic supplements. The nanopatterns (100 nm depth, $120 \mathrm{~nm}$ diameter nanopits) consisted on either ordered square 
(SQ) or hexagonal (HEX) arrays or, disordered square arrays with pits displaced randomly by up to $50 \mathrm{~nm}$ (from the true ordered position, DSQ50) or randomly distributed pits (RAND). The absolute or average centre-to-centre spacing was, in all of the variants, $300 \mathrm{~nm}$. Osteoprogenitor cells and MSCs were cultured for 21 days in maintenance media on the different patterns and showed, for both cell types, a decreased cell density on ordered SQ and HEX arrays, as compared to flat substrates. RAND substrates showed a higher density of cells after 21 days of culture, but limited expression of common osteogenic markers such as osteopontin and osteocalcin, as detected by immunohistochemistry. Osteoprogenitors and MSCs cultured in DSQ50 substrates showed the highest cell density, presenting aggregates of cells reminiscent of bone nodules, and increased levels of osteopontin and osteocalcin as compared to flat, ordered and RANS substrates. Moreover, MSCs cultured for 28 days on DSQ50 substrates, in maintenance media, showed significant calcium phosphate deposition when stained with Alizarin Red.

Similarly, other studies have shown the potential of determined topographical micropatterns to induce the differentiation of MSCs towards osteogenic phenotypes in the absence of induction media, highlighting the idea that a stiff, structured substrate that mimics the native structure of the bone cell microenvironment can support the induction of osteogenic lineage choice in MSCs. The most inductive nanopattern, although not fully defined yet, appears to be that one that promotes the elongation of the cells to acquire a spindle-like morphology, similar to that one found in the native tissue (Unadkat et al., 2011; Watari et al., 2012; Zhao et al., 2012).

Many studies have thus confirmed the influence of pattern shape, size or density on stem cell behaviours and their ability to drive a chondrogenic or osteogenic fate choice, however, translating of these 2D-derived insight into a 3D environment remains challenging. 


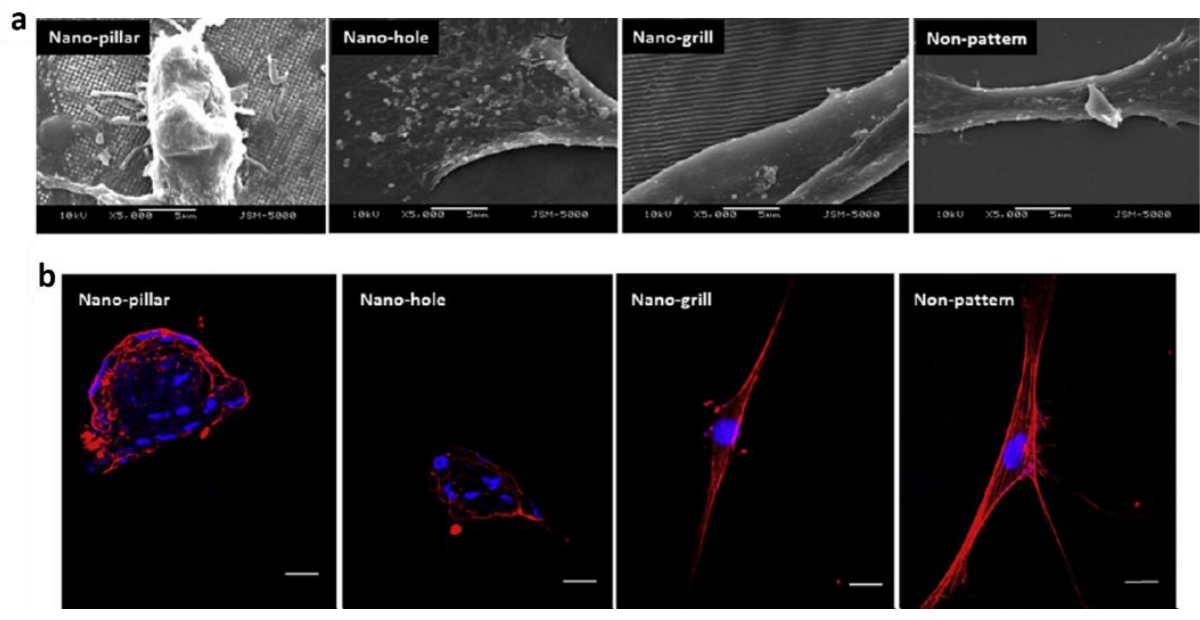

Figure 5. (a) Scanning electron microscopy images of hMSCs cultured for $48 \mathrm{~h}$ on different substrate topographies showing rounded, polygonal or spindle morphologies when cultured on nano-pillar, nanoholes and nano-grills, respectively. Scale bares are $5 \mu \mathrm{m}$. (b) F-actin (red) organization on hMSCs cultured for 3 days on the same substrates showing cells with rounded morphology when cultured on nano-pillar or nano-holes and, spindle morphologies when cultured on nano-grills or non-patterned surfaces. Nucleus (DNA) is labelled in blue and scale bars are $1 \mu \mathrm{m}$. Reprinted from Nanomedicine: Nanotechnology, Biology, and Medicine, 10 (7). Wu, Y.-N.; Law, J. B. K.; He, A. Y.; Low, H. Y.; Hui, J. H. P.; Lim, C. T.; Yang, Z.; Lee, E. H., Substrate topography determines the fate of chondrogenesis from human mesenchymal stem cells resulting in specific cartilage phenotype formation. (C) 2014 with permission from Elsevier.

\section{Mimicking matrix mechanical properties in osteochondral tissue.}

Cells resident in different tissues are in contact with ECM molecules and their associated nanothrough to micro-size tertiary structures that contribute to the cell experiencing a range of different mechanical properties, or in sum, different viscoelasticities. A chondrocyte resides within a collagen and GAG-rich matrix that is highly dissipative and of medium elasticity (highly viscoelastic, medium stiffness), whilst an osteoblast is adhered to the subchondral bone, a matrix that has low or non-existent dissipative character and very high elasticity (low viscoelasticity, very high stiffness). 
It has been shown by numerous researchers that mimicking these in vivo tissue mechanics within in vitro culture can induce changes in cell phenotype. MSCs cultured on substrates of different mechanical properties have been shown to display stiffness-dependant changes in cell morphology, proliferation, migration, and commitment to differentiate towards different tissue cell lineages (Figure 6, a) (Engler et al., 2006; Park et al., 2011; Rowlands et al., 2008). Cameron et al.(Cameron et al., 2011; Cameron et al., 2014) further decoupled the overall mechanical properties of culture substrates to better represent the viscoelastic nature of native tissues, by designing a series of polyacrylamide hydrogel substrates of varying levels of viscoelasticity but constant values of stiffness (that is, they had a constant elastic modulus but varying loss modulus). MSC morphology, proliferation and differentiation potential were highly dependent on substrate viscoelasticity. Moreover, these studies proved that the observed differences on cell behaviour were related to the reduction on isometric (via actin-myosin contraction) cytoskeletal tension due to the dissipative character of these substrates (which engendered an inherent ability to 'creep' or plastically deform under imposed cellular forces) encouraging stress relaxation in the cells. They observed a decreased focal adhesion length with increased loss moduli (dissipation), which correlated with a more motile spreading of the cells, and increased final cell spread area (Figure 6, b). The mechanism by which the formation of focal adhesion regulates cell behaviour has been lately proposed to be related to the integrin activation of $\beta$-catenin, which in turn, up-regulates Wnt signalling that is known to contribute to the differentiation of MSCs (Du et al., 2016). 

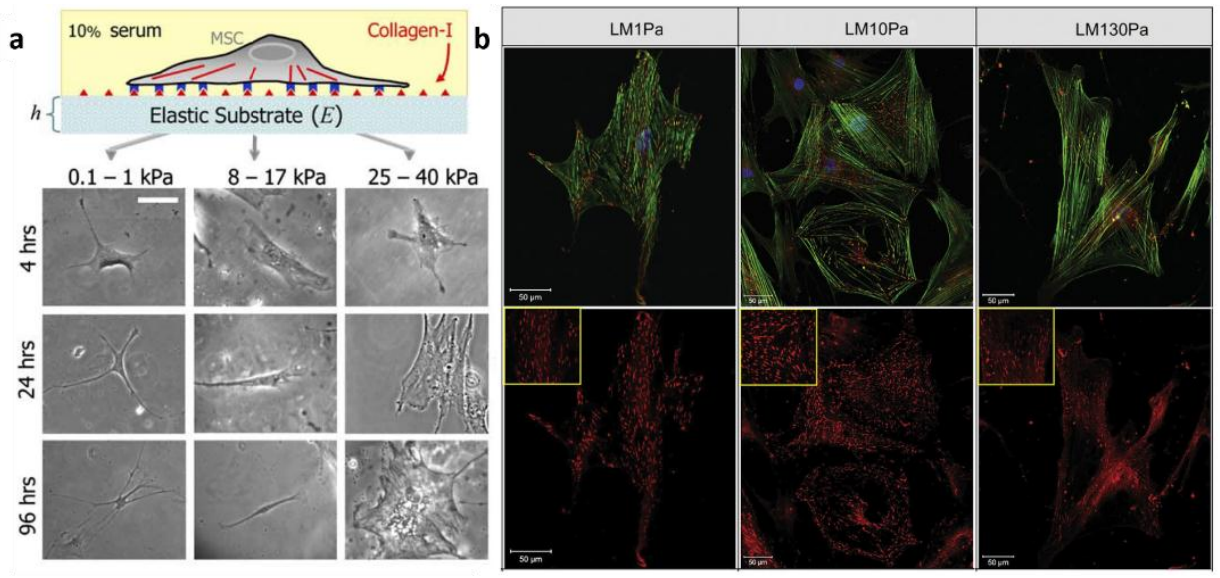

Figure 6. Cell adhesion onto substrates with different stiffness or loss moduli. (a) Development of different cell morphologies on hMSCs cultured for 4, 24 and $96 \mathrm{~h}$ in substrates of varying elastic modulus. Scale bar is $20 \mu \mathrm{m}$. Reprinted from Cell, 126 (4), Engler, A. J.; Sen, S.; Sweeney, H. L.; Discher, D. E., Matrix elasticity directs stem cell lineage specification. (C) 2006 with permission from Elsevier. (b) hMSCs cultured on substrates with varying loss moduli showing an increase on the length of focal adhesion points (vinculin, red) and spread area with decreased loss modulus. Cells were stained for actin (green), nucleus (blue) and vinculin (red). Scale bars are $50 \mu \mathrm{m}$. Reprinted from Biomaterials, 32 (26), Cameron, A. R.; Frith, J. E.; Cooper-White, J. J., The influence of substrate creep on mesenchymal stem cell behaviour and phenotype. (C) 2011 with permission from Elsevier.

Springboarding from these insights, several studies have focused their attention on the effect of matrix stiffness (Young's modulus) on the maintenance of chondrogenic phenotypes or chondrogenic differentiation of MSCs. Schuh et al.(Schuh et al., 2009) reported on the effect of hydrogels with varying Young's modulus $(4,10,40$ and $100 \mathrm{kPa})$ on the maintenance of phenotype of monolayer cultured primary chondrocytes. They showed that hydrogels of lower Young's modulus ( $4 \mathrm{kPa}$ ) were better able to maintain the phenotype of cultured chondrocytes, as observed by higher expression levels of collagen type II and aggrecan. This findings correlated with a rounded morphology and lower proliferation levels of chondrocytes cultured on this substrates and, with previous studies (Wu et al., 2014). In a similar study, Toh et al.(Toh et al., 2012) showed that MSCs under chondrogenic induction media that were encapsulated in hydrogels with lower compressive modulus (5 vs $11 \mathrm{kPa}$ ) displayed a more rounded 
morphology and had higher biosynthesis rates of GAGs and collagen type II than in stiffer (11 $\mathrm{kPa}$ ) hydrogels.

Although it appears from investigations to date that a matrix with a lower level of stiffness is preferred when wanting to induce or maintain chondrogenic phenotypes, whilst the opposite is true for osteogenic phenotypes, where a higher level of stiffness is supportive, it is however difficult to decouple this effect from substrate composition, ligand availability or pore size, as varying the mechanical properties using the same polymeric matrix relies on one changing the cross-linking density, which will change the number of available functional groups, ligand density and matrix permeability (Rowlands et al., 2008; Trappmann et al., 2012; Watt and Huck, 2013; Wen et al., 2014). Furthermore, it has been shown that even on stiff substrates, osteogenic commitment is only supported if the correct ligand (one that will itself support osteogenic commitment (e.g. collagen 1, fibronectin)) is present on the substrate (Rowlands et al., 2008). Nevertheless, matrix mechanical properties do indeed play a crucial role in chondrogenic and osteogenic differentiation and thus the local mechanical property slate of the surrounding ECM needs to be considered in designing scaffolds for osteochondral repair.

\section{Bringing it all together - Multi-layered osteochondral mimics}

It is important to acknowledge that the native extracellular matrix surrounding cells in tissues combines all the aforementioned surface parameters, i.e., spatially controlled chemistry, topography and specific mechanical properties, to support cell viability and phenotype. These combined parameters are not only relevant at nanometer to micrometer length-scales, but span the different zones found within articular cartilage and osteochondral tissue. Many researchers have attempted to recreate these different structures using scaffolds that mimic the multi-layer composition of osteochondral defects and succeeded to some extent (Barron et al., 2016; Dormer et al., 2012; Dresing et al., 2014; Jeon et al., 2014a; Nooeaid et al., 2014; Nooeaid et 
al., 2012). However, mimicking the spatiotemporal chemistry and topography is still a challenge.

In the recent past, multi-layered or stratified scaffolds targeting osteochondral repair consisted of only two distinct zones resembling the bone-cartilage interface either chemically, mechanically or structurally (Chen et al., 2011; Gentile et al., 2012; Jin et al., 2014; Li et al., 2015; Nooeaid et al., 2014; Rodrigues et al., 2012; Steele et al., 2014). However, these approaches lacked the ability to mimic the architecture of articular cartilage, leading to isotropic cartilaginous tissues that fail to resemble the structure and depth-dependant characteristic of native tissue, and consequently, its mechanical properties.

Levingstone et al.(Levingstone et al., 2014) fabricated a multilayer scaffold by applying several steps of casting and freeze-drying polymer solutions of different concentration. They obtained multi-layer scaffolds with varying pore sizes, making a bone phase, an intermediate phase and a cartilage phase. They implanted these scaffolds into caprine stifle joint osteochondral defect models and evaluated the outcome after up to 12 months of implantation (Levingstone et al., 2016). Radiological analysis of the defects after 2 weeks of implantation showed superior subchondral bone formation, as compared to market approved implants. After 12 months, the formation of hyaline-like tissue was observed with a well-defined tidemark, as characterized by histological analysis. However, the structure of this neotissue was not comprehensively compared to native tissue.

Recently, additive manufacturing techniques have been employed to develop scaffolds with mechanical, chemical or physical parameters, such as surface energy, that mimic the native osteochondral environment (Andrea Di et al., 2016; Holmes et al., 2014). Moroni and coworkers recently developed and fabricated scaffolds with discrete macroscopic gradients of deposited poly(ethylene oxide terephthalate)/poly(butylene terephthalate) (PEOT/PBT), 
poly(lactic acid) (PLA) and polycaprolactone (PCL), which accounted for either gradient stiffness or gradient surface energies and wettability that resembled that of the osteochondral environment (Andrea Di et al., 2016). PLA-PEOT/PBT-PCL scaffolds accounted for a gradient in wettability (labelled as WG), whilst PLA-PCL-PEOT/PBT scaffolds accounted for a gradient in stiffness (labelled as SG). Culture of hMSCS on the scaffolds for seven days revealed that, in osteogenic medium, PEOT/PBT regions (lowest mechanical properties) of the SG scaffold showed higher levels of ALP activity with respect to PLA and PCL regions, whilst a similar effect was only observed after 28 days of culture in the WG scaffolds. To the contrary, when hMSCs were cultured on these scaffolds in chondrogenic media no significant differences were observed in glycosaminoglycan deposition after 7 or 28 days of culture in the SG scaffolds, whilst in the WG scaffolds a higher deposition of GAGs was measured in the PLA region (stiffest region) as compared to the other gradient scaffold and individual regions within it. This study highlights the importance of the biomaterial properties not only at a molecular level but also at a macroscopic scale.

An alternate approach to regenerating osteochondral defects was recently published by Zhu $e t$ al.(Zhu et al., 2014), who prepared stratified scaffolds that accounted for four different layers, three for cartilage and one for subchondral bone, with varying compositions and mechanical properties. The scaffolds were composed of a chitosan-polycaprolactone copolymer loaded with varying ratios of collagen and chondroitin sulphate. The superficial layer mimic accounted for the highest concentration of collagen and lowest of chondroitin sulphate, whilst the deep zonal layer mimic was composed of lowest concentration of collagen and highest of the GAG. This stratified porous scaffold also accounted for gradient mechanical properties and pore size, with the strongest and most porous layer in the deepest zone, which was achieved by varying concentrations of the copolymer. 
Most recently, multi-layered scaffolds with depth-dependant structures were reported by Camarero-Espinosa et al.(Camarero-Espinosa et al., 2016c) These scaffolds accounted for a superficial tubular layer oriented parallel to the surface, a middle porous isotropic layer and a deep tubular zone with the tubules aligned orthogonally to subchondral bone. They also incorporated spatially controlled chemistry and mechanical properties, imparted through the use of cellulose nanocrystals carrying different surface moieties (Figure 7 a, b and e). In this particular study, the introduction of CNCs guided chondrocyte morphology and promoted the deposition of a GAG-rich matrix when functionalized with sulphate groups (S-CNCs) and incorporated on the middle porous layer, or the formation of hydroxyapatite via exposure to $\mathrm{CaCl}_{2}$ (3 days) and simulated body fluid (7 days) when functionalized with phosphate groups (P-CNCs) and incorporated on the deep layer, respectively (Figure 7, $\mathbf{c}$ and d). These scaffolds showed, after 4 weeks of in-vitro chondrocyte culture, the capability of directing the cell growth and the deposition of a hyaline-like ECM (Figure 7, c). The ability of such a system to achieve improved outcomes within an osteochondral model in vivo remains to be tested.

In a similar study, Moeinzadeh et al. (Moeinzadeh et al., 2016) developed a multi-layered scaffolds with zone-dependant stiffness, composition and structure orientation for cartilage tissue engineering. These scaffolds were based on PLA electrospun microfibers with orientations that vary from parallel to random to perpendicular for the superficial, middle and calcified zones, respectively. The fibrous scaffolds were embed into a hydrogel matrix of star acrylate-terminated lactide-chain-extended polyethylene glycol macromer (SPELA) and acrylamide terminated RGD peptide. The hydrogel was synthetized with varying ratios of lactide and polyethylene glycol, thus tuning the mechanical properties of the scaffold in the different layers with $0.08,2.1$ and $320 \mathrm{MPa}$ for the superficial, middle and calcified layers respectively. During the gelation process via UV crosslinking, different growth factors and cell densities were incorporated into the different scaffold layers. The superficial layer contained 
TGF- $\beta 1$ and BMP-7, the middle layer TGF- $\beta 1$ and IGF-7 and the calcified layer contained TGF- $\beta 1$ and HA. They evaluated the effect of these different parameters, i.e. varying composition, mechanical properties and structure, on the differentiation potential of cultured hMSCs in chondrogenic media for up to 21 days, by means of protein deposition and gene expression. They reported a higher influence of the mechanical properties (over chemical or structural) for the differentiation of MSCs towards superficial- and calcified-zone phenotypes, while the fibre alignment had a strong influence on the deposition of a collagen II matrix and the growth factor delivery had a dominant influence on the middle-zone chondrogenic differentiation.

a)

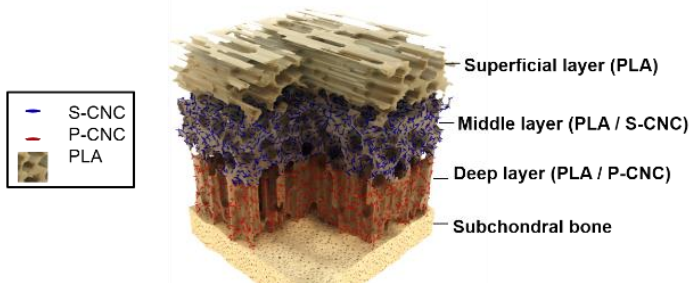

b)

SEM c) LSM

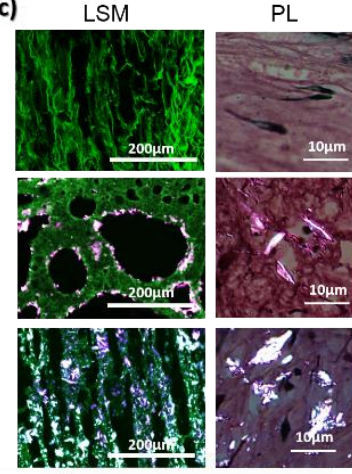

d) Deep layer before
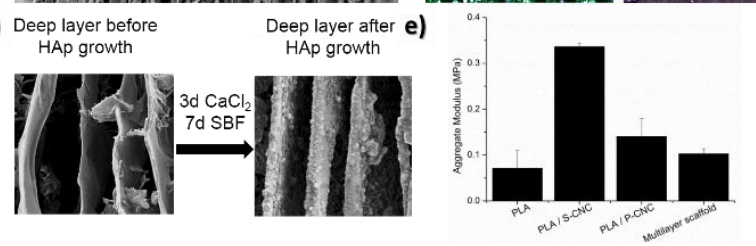

Figure 7. Multi-layer scaffolds with spatially controlled structure, chemistry and mechanical properties for osteochondral tissue engineering. a) Schematic representation of the multi-layer design of the composite scaffolds based on polylactide (PLA) and sulphated- and phosphated- cellulose nanocrystals (S-CNCs and P-CNCs, respectively), mimicking the structure of the native mature articular cartilage. b) Scanning electron microscopy (SEM) cross-section image of the multi-layer scaffolds. c) Light scanning microscopy (LSM) images of the individual layers of the scaffold showing the controlled 
localization of the CNCs (green: Alexa-488, scaffold. Pink: Rhodamine functionalized-CNCs) and polarized light microscopy (PL) images of Safranine-O stained sections of engineered cartilage within the multi-layer scaffold showing the distinct orientation of chondrocytes within and the location of the CNCs (Birefringent: CNCs; red-pink: GAGs; black: chondrocytes). d) SEM images of the deep layer of the scaffolds before and after exposure to $\mathrm{CaCl}_{2}$ (3 days) and simulated body fluid (SBF, 7 days) showing in the latter a granulated coating corresponding to the formation of hydroxyapatite. e) Aggregate modulus of the individual and combined (multi-layer) layers of the scaffold calculated from semi-confined equilibrium compression experiments. Modified from Biomaterials, (74) 42-52, Camarero-Espinosa et al., Directed cell growth in multi-zonal scaffolds for cartilage tissue engineering, (C) (2015), with permission from Elsevier.

\section{Conclusion}

Clinical approaches to regenerate osteochondral defects commonly lead to the formation of unstructured tissues, which lack adequate mechanical properties to withstand the loads applied into the joint. The main reason for the formation of such isotropic neocartilage is the lack of cell guidance cues that in turn results on inadequate differentiation of recruited MSCs (through microfracture or exogenous implantation) in the defect site. Native cartilage cells, i.e., chondrocytes, are quiescent and therefore regeneration of such tissues requires tissue engineers to rethink repair and consider mimicking critical developmental cues that occur during joint development, including processes that drive condensation of the MSCs, spatial patterning and differentiation towards the distinct phenotypes found within the multiple layers of this complex tissue. We must start by understanding how to present cells that are inherently plastic (i.e. able to differentiate) with the spatiotemporal and architectural cues that will drive them to reproduce such tissue specification and patterning. In this review, we have summarized the state-of-theart techniques aimed at achieving tissue engineering of osteochondral defects, focusing on the different approaches to tailor biomaterial substrates and scaffolds. These included the use of 
spatially controlled chemical cues, topographical features and the importance of matrix mechanical properties, finishing with some key examples of researchers attempts to combine these techniques into macro-scale, multi-layered, functional osteochondral mimics. Altogether, whilst the field has certainly made significant progress over the past twenty years, we still lack a viable tissue engineered solution to functional osteochondral tissue repair. There is a dire need to develop greater capabilities to mimic native ECM property slates, and greater understanding of the critical, minimal cues required to achieve directed differentiation of MSCs towards each of the chondrocytic and osteocytic phenotypes within the multiple layers of this complex tissue, using ideally endogenous marrow-derived stem cells.

\section{Acknowledgements}

The authors thank Mikel Vicente Pulido for the art-work shown in Figure 1. This work was financially supported by the Swiss National Science Foundation (Project P2FRP2_158734), the Australian Research Council Discovery Grants Scheme (DP140104217) and the National Health and Medical Research Council Project Grants Scheme (APP1060340).

\section{References}

Alimperti, S., Andreadis, S.T., 2015. CDH2 and CDH11 act as regulators of stem cell fate decisions. Stem Cell Research 14, 270-282.

Amler, E., Filova, E., Buzgo, M., Prosecka, E., Rampichova, M., Necas, A., Nooeaid, P., Boccaccini, A.R., 2014. Functionalized nanofibers as drug-delivery systems for osteochondral regeneration. Nanomedicine 9, 1083-1094.

Anderson, H.C., Garimella, R., Tague, S.E., 2005. The role of matrix vesicles in growth plate development and biomineralization. Frontiers in Bioscience-Landmark 10, 822-837.

Andrea Di, L., Alessia, L., Giuseppe, C., Ivan, L.-M., Michel, K.-G., Julius, V., Clemens van, B., Carlos, M., Lorenzo, M., 2016. Surface energy and stiffness discrete gradients in additive manufactured scaffolds for osteochondral regeneration. Biofabrication 8, 015014.

Arnsdorf, E.J., Tummala, P., Kwon, R.Y., Jacobs, C.R., 2009. Mechanically induced osteogenic differentiation - the role of RhoA, ROCKII and cytoskeletal dynamics. Journal of Cell Science 122, 546-553. 
Arslan, E., Guler, M.O., Tekinay, A.B., 2016. Glycosaminoglycan-Mimetic Signals Direct the Osteo/Chondrogenic Differentiation of Mesenchymal Stem Cells in a Three-Dimensional Peptide Nanofiber Extracellular Matrix Mimetic Environment. Biomacromolecules 17, 1280-1291.

Athanasiou, K.A., Darling, E.M., Hu, J.C., 2009. Articular Cartilage Tissue Engineering. Synthesis Lectures on Tissue Engineering 1, 1-182.

Barron, V., Neary, M., Mohamed, K.M.S., Ansboro, S., Shaw, G., O'Malley, G., Rooney, N., Barry, F., Murphy, M., 2016. Evaluation of the Early In Vivo Response of a Functionally Graded Macroporous Scaffold in an Osteochondral Defect in a Rabbit Model. Annals of Biomedical Engineering 44, 18321844.

Benoit, D.S.W., Schwartz, M.P., Durney, A.R., Anseth, K.S., 2008. Small functional groups for controlled differentiation of hydrogel-encapsulated human mesenchymal stem cells. Nature Materials $7,816-$ 823.

Benya, P.D., Shaffer, J.D., 1982. Dedifferentiated chondrocytes reexpress the differentiated collagen phenotype when cultured in agarose gels. Cell 30, 215-224.

Bian, L., Guvendiren, M., Mauck, R.L., Burdick, J.A., 2013. Hydrogels that mimic developmentally relevant matrix and $\mathrm{N}$-cadherin interactions enhance MSC chondrogenesis. Proceedings of the National Academy of Sciences of the United States of America 110, 10117-10122.

Biesalski, M.A., Knaebel, A., Tu, R., Tirrell, M., 2006. Cell adhesion on a polymerized peptideamphiphile monolayer. Biomaterials 27, 1259-1269.

Blanco, F.J., Guitian, R., Vazquez-Martul, E., de Toro, F.J., Galdo, F., 1998. Osteoarthritis chondrocytes die by apoptosis - A possible pathway for osteoarthritis pathology. Arthritis and Rheumatism 41, 284-289.

Boateng, S.Y., Lateef, S.S., Mosley, W., Hartman, T.J., Hanley, L., Russell, B., 2005. RGD and YIGSR synthetic peptides facilitate cellular adhesion identical to that of laminin and fibronectin but alter the physiology of neonatal cardiac myocytes. American Journal of Physiology-Cell Physiology 288, C30-C38.

Bodin, A., Ahrenstedt, L., Fink, H., Brumer, H., Risberg, B., Gatenholm, P., 2007. Modification of nanocellulose with a xyloglucan-RGD conjugate enhances adhesion and proliferation of endothelial cells: Implications for tissue engineering. Biomacromolecules 8, 3697-3704.

Brittberg, M., Lindahl, A., Nilsson, A., Ohlsson, C., Isaksson, O., Peterson, L., 1994. Treatment of deep cartilage defects in the knee with autologous chondrocyte transplantation. New England Journal of Medicine 331, 889-895.

Buckwalter, J.A., 2002. Articular cartilage injuries. Clinical Orthopaedics and Related Research 402, 21 37.

Burridge, P.W., Keller, G., Gold, J.D., Wu, J.C., 2012. Production of De Novo Cardiomyocytes: Human Pluripotent Stem Cell Differentiation and Direct Reprogramming. Cell Stem Cell 10, 16-28.

Camarero-Espinosa, S., Cooper-White, J.J., 2016. Controlled differentiation of mesenchymal stem cells towards distinctive chondrogenic phenotypes for tailored articular cartilage tissue engineering. Eropean Cells and Materials 31, 20.

Camarero-Espinosa, S., Rothen-Rutishauser, B., Foster, E.J., Weder, C., 2016a. Articular cartilage: from formation to tissue engineering. Biomaterials Science 4, 734-767.

Camarero-Espinosa, S., Rothen-Rutishauser, B., Foster, E.J., Weder, C., 2016b. Articular cartilage: from formation to tissue engineering. Biomaterials Science.

Camarero-Espinosa, S., Rothen-Rutishauser, B., Weder, C., Foster, E.J., 2016c. Directed cell growth in multi-zonal scaffolds for cartilage tissue engineering. Biomaterials 74, 42-52.

Camarero Espinosa, S., Kuhnt, T., Foster, E.J., Weder, C., 2013. Isolation of thermally stable cellulose nanocrystals by phosphoric acid hydrolysis. Biomacromolecules 14, 1223-1230.

Cameron, A.R., Frith, J.E., Cooper-White, J.J., 2011. The influence of substrate creep on mesenchymal stem cell behaviour and phenotype. Biomaterials 32, 5979-5993. 
Cameron, A.R., Frith, J.E., Gomez, G.A., Yap, A.S., Cooper-White, J.J., 2014. The effect of timedependent deformation of viscoelastic hydrogels on myogenic induction and Rac1 activity in mesenchymal stem cells. Biomaterials 35, 1857-1868.

Capadona, J.R., Shanmuganathan, K., Tyler, D.J., Rowan, S.J., Weder, C., 2008. Stimuli-responsive polymer nanocomposites inspired by the sea cucumber dermis. Science 319, 1370-1374.

Carvalho, R.S., Kostenuik, P.J., Salih, E., Bumann, A., Gerstenfeld, L.C., 2003. Selective adhesion of osteoblastic cells to different integrin ligands induces osteopontin gene expression. Matrix Biology 22, 241-249.

Chen, J., Chen, H., Li, P., Diao, H., Zhu, S., Dong, L., Wang, R., Guo, T., Zhao, J., Zhang, J., 2011. Simultaneous regeneration of articular cartilage and subchondral bone in vivo using MSCs induced by a spatially controlled gene delivery system in bilayered integrated scaffolds. Biomaterials 32 , 4793-4805.

Chen, S.S., Falcovitz, Y.H., Schneiderman, R., Maroudas, A., Sah, R.L., 2001. Depth-dependent compressive properties of normal aged human femoral head articular cartilage: relationship to fixed charge density. Osteoarthritis and Cartilage 9, 561-569.

Cohen, N.P., Foster, R.J., Mow, V.C., 1998. Composition and dynamics of articular cartilage: Structure, function, and maintaining healthy state. Journal of Orthopaedic \& Sports Physical Therapy 28, 203215.

Connelly, J.T., Garcia, A.J., Levenston, M.E., 2007. Inhibition of in vitro chondrogenesis in RGDmodified three-dimensional alginate gels. Biomaterials 28, 1071-1083.

Connelly, J.T., Petrie, T.A., Garcia, A.J., Levenston, M.E., 2011. FIBRONECTIN- AND COLLAGENMIMETIC LIGANDS REGULATE BONE MARROW STROMAL CELL CHONDROGENESIS IN THREEDIMENSIONAL HYDROGELS. European Cells \& Materials 22, 168-177.

Coraux, C., Nawrocki-Raby, A., Hinnrasky, J., Kileztky, C., Gaillard, D., Dani, C., Puchelle, E., 2005. Embryonic stem cells generate airway epithelial tissue. American Journal of Respiratory Cell and Molecular Biology 32, 87-92.

Dalby, M.J., Gadegaard, N., Tare, R., Andar, A., Riehle, M.O., Herzyk, P., Wilkinson, C.D.W., Oreffo, R.O.C., 2007. The control of human mesenchymal cell differentiation using nanoscale symmetry and disorder. Nat Mater 6, 997-1003.

DeKosky, B.J., Dormer, N.H., Ingavle, G.C., Roatch, C.H., Lomakin, J., Detamore, M.S., Gehrke, S.H., 2010. Hierarchically Designed Agarose and Poly(Ethylene Glycol) Interpenetrating Network Hydrogels for Cartilage Tissue Engineering. Tissue Engineering Part C-Methods 16, 1533-1542.

Diener, A., Nebe, B., Lüthen, F., Becker, P., Beck, U., Neumann, H.G., Rychly, J., 2005. Control of focal adhesion dynamics by material surface characteristics. Biomaterials 26, 383-392.

Dormer, N.H., Singh, M., Zhao, L., Mohan, N., Berkland, C.J., Detamore, M.S., 2012. Osteochondral interface regeneration of the rabbit knee with macroscopic gradients of bioactive signals. Journal of Biomedical Materials Research Part A 100A, 162-170.

Dresing, I., Zeiter, S., Auer, J., Alini, M., Eglin, D., 2014. Evaluation of a press-fit osteochondral poly(ester-urethane) scaffold in a rabbit defect model. Journal of Materials Science-Materials in Medicine 25, 1691-1700.

Du, J., Zu, Y., Li, J., Du, S., Xu, Y., Zhang, L., Jiang, L., Wang, Z., Chien, S., Yang, C., 2016. Extracellular matrix stiffness dictates Wnt expression through integrin pathway. Scientific Reports 6, 20395.

Dugan, J.M., Collins, R.F., Gough, J.E., Eichhorn, S.J., 2013. Oriented surfaces of adsorbed cellulose nanowhiskers promote skeletal muscle myogenesis. Acta Biomaterialia 9, 4707-4715.

Dugan, J.M., Gough, J.E., Eichhorn, S.J., 2010. Directing the Morphology and Differentiation of Skeletal Muscle Cells Using Oriented Cellulose Nanowhiskers. Biomacromolecules 11, 2498-2504.

Duncan, A.W., Dorrell, C., Grompe, M., 2009. Stem Cells and Liver Regeneration. Gastroenterology 137, 466-481.

Elsayed, M., Merkel, O.M., 2014. Nanoimprinting of topographical and 3D cell culture scaffolds. Nanomedicine 9, 349-366. 
Engler, A.J., Sen, S., Sweeney, H.L., Discher, D.E., 2006. Matrix elasticity directs stem cell lineage specification. Cell 126, 677-689.

Eyre, D., 2002. Collagen of articular cartilage. Arthritis Research \& Therapy 4, 30-35.

Eyre, D.R., 1991. The collagens of articular-cartilage. Seminars in Arthritis and Rheumatism 21, 2-11.

Eyre, D.R., Wu, J.J., 1995. Collagen structure and cartilage matrix integrity. The Journal of rheumatology. Supplement 43, 82-85.

Filardo, G., Kon, E., Perdisa, F., Balboni, F., Marcacci, M., 2014. Autologous osteochondral transplantation for the treatment of knee lesions: results and limitations at two years' follow-up. International Orthopaedics 38, 1905-1912.

Flannery, C.R., Hughes, C.E., Schumacher, B.L., Tudor, D., Aydelotte, M.B., Kuettner, K.E., Caterson, B., 1999. Articular cartilage superficial zone protein (SZP) is homologous to megakaryocyte stimulating factor precursor and is a multifunctional proteoglycan with potential growth-promoting, cytoprotective, and lubricating properties in cartilage metabolism. Biochemical and Biophysical Research Communications 254, 535-541.

Frith, J.E., Mills, R.J., Cooper-White, J.J., 2012a. Lateral spacing of adhesion peptides influences human mesenchymal stem cell behaviour. Journal of Cell Science 125, 317-327.

Frith, J.E., Mills, R.J., Hudson, J.E., Cooper-White, J.J., 2012b. Tailored Integrin-Extracellular Matrix Interactions to Direct Human Mesenchymal Stem Cell Differentiation. Stem Cells and Development 21, 2442-2456.

Fujioka, R., Aoyama, T., Takakuwa, T., 2013. The layered structure of the articular surface. Osteoarthritis and Cartilage 21, 1092-1098.

Furukawa, T., Eyre, D.R., Koide, S., Glimcher, M.J., 1980. Biochemical-studies on repair cartilage resurfacing experimental defects in the rabbit knee. Journal of Bone and Joint Surgery-American Volume 62, 79-89.

Geiger, B., Spatz, J.P., Bershadsky, A.D., 2009. Environmental sensing through focal adhesions. Nat Rev Mol Cell Biol 10, 21-33.

Gentile, P., Chiono, V., Tonda-Turo, C., Mattu, C., Baino, F., Vitale-Brovarone, C., Ciardelli, G., 2012. Bioresorbable glass effect on the physico-chemical properties of bilayered scaffolds for osteochondral regeneration. Materials Letters 89, 74-76.

George, P.A., Quinn, K., Cooper-White, J.J., 2010. Hierarchical scaffolds via combined macro- and micro-phase separation. Biomaterials 31, 641-647.

Habibi, N., Kamaly, N., Memic, A., Shafiee, H., 2016. Self-assembled peptide-based nanostructures: Smart nanomaterials toward targeted drug delivery. Nano Today 11, 41-60.

Hangody, L., Fules, P., 2003. Autologous osteochondral mosaicplasty for the treatment of fullthickness defects of weight-bearing joints - Ten years of experimental and clinical experience. Journal of Bone and Joint Surgery-American Volume 85A, 25-32.

Hennessy, K.M., Pollot, B.E., Clem, W.C., Phipps, M.C., Sawyer, A.A., Culpepper, B.K., Bellis, S.L., 2009. The effect of collagen I mimetic peptides on mesenchymal stem cell adhesion and differentiation, and on bone formation at hydroxyapatite surfaces. Biomaterials 30, 1898-1909.

Hoemann, C.D., Lafantaisie-Favreau, C.-H., Lascau-Coman, V., Chen, G., Guzman-Morales, J., 2012. The cartilage-bone interface. The journal of knee surgery 25.

Holmes, B., Zhu, W., Li, J., Lee, J.D., Zhang, L.G., 2014. Development of Novel Three-Dimensional Printed Scaffolds for Osteochondral Regeneration. Tissue Engineering Part A 21, 403-415.

Holtzer, H., Abbott, J., Lash, J., Holtzer, S., 1960. THE LOSS OF PHENOTYPIC TRAITS BY DIFFERENTIATED CELLS IN VITRO .1. DEDIFFERENTIATION OF CARTILAGE CELLS. Proceedings of the National Academy of Sciences of the United States of America 46, 1533-1542.

Huey, D.J., Hu, J.C., Athanasiou, K.A., 2012. Unlike Bone, Cartilage Regeneration Remains Elusive. Science 338, 917-921.

Humphries, J.D., Byron, A., Humphries, M.J., 2006. Integrin ligands at a glance. Journal of Cell Science 119, 3901-3903. 
Hunziker, E.B., Michel, M., Studer, D., 1997. Ultrastructure of adult human articular cartilage matrix after cryotechnical processing. Microscopy Research and Technique 37, 271-284.

Jayawarna, V., Richardson, S.M., Hirst, A.R., Hodson, N.W., Saiani, A., Gough, J.E., Ulijn, R.V., 2009. Introducing chemical functionality in Fmoc-peptide gels for cell culture. Acta Biomaterialia 5, 934943.

Jeon, J.E., Vaquette, C., Klein, T.J., Hutmacher, D.W., 2014a. Perspectives in Multiphasic Osteochondral Tissue Engineering. Anatomical Record-Advances in Integrative Anatomy and Evolutionary Biology 297, 26-35.

Jeon, J.E., Vaquette, C., Theodoropoulos, C., Klein, T.J., Hutmacher, D.W., 2014b. Multiphasic construct studied in an ectopic osteochondral defect model. Journal of the Royal Society Interface 11, 1-14.

Jha, A.K., Malik, M.S., Farach-Carson, M.C., Duncan, R.L., Jia, X., 2010. Hierarchically structured, hyaluronic acid-based hydrogel matrices via the covalent integration of microgels into macroscopic networks. Soft Matter 6, 5045-5055.

Ji, W., Sun, Y., Yang, F., van den Beucken, J.J.J.P., Fan, M., Chen, Z., Jansen, J.A., 2011. Bioactive Electrospun Scaffolds Delivering Growth Factors and Genes for Tissue Engineering Applications. Pharmaceutical Research 28, 1259-1272.

Jiang, Y., Chen, J., Deng, C., Suuronen, E.J., Zhong, Z., 2014. Click hydrogels, microgels and nanogels: Emerging platforms for drug delivery and tissue engineering. Biomaterials 35, 4969-4985.

Jin, G.-Z., Kim, J.-J., Park, J.-H., Seo, S.-J., Kim, J.-H., Lee, E.-J., Kim, H.-W., 2014. Biphasic nanofibrous constructs with seeded cell layers for osteochondral repair. Tissue engineering. Part $\mathrm{C}$, Methods 20, 895-904.

Joergensen, N.L., Le, D.Q.S., Andersen, O.Z., Foss, M., Danielsen, C.C., Foldager, C.B., Lind, M., Lysdahl, H., 2015. Topography-Guided Proliferation: Distinct Surface Microtopography Increases Proliferation of Chondrocytes In Vitro. Tissue Engineering Part A 21, 2757-2765.

Johnstone, B., Hering, T.M., Caplan, A.I., Goldberg, V.M., Yoo, J.U., 1998. In vitro chondrogenesis of bone marrow-derived mesenchymal progenitor cells. Experimental Cell Research 238, 265-272.

Jorfi, M., Foster, E.J., 2015. Recent advances in nanocellulose for biomedical applications. Journal of Applied Polymer Science 132, n/a-n/a.

Jung, Y., Chung, Y.-I., Kim, S.H., Tae, G., Kim, Y.H., Rhie, J.W., Kim, S.-H., Kim, S.H., 2009. In situ chondrogenic differentiation of human adipose tissue-derived stem cells in a TGF-beta(1) loaded fibrin-poly(lactide-caprolactone) nanoparticulate complex. Biomaterials 30, 4657-4664.

Kalaskar, D.M., Gough, J.E., Ulijn, R.V., Sampson, W.W., Scurr, D.J., Rutten, F.J., Alexander, M.R., Merry, C.L.R., Eichhorn, S.J., 2008. Controlling cell morphology on amino acid-modified cellulose. Soft Matter 4, 1059-1065.

Karpiak, J.V., Ner, Y., Almutairi, A., 2012. Density Gradient Multilayer Polymerization for Creating Complex Tissue. Advanced Materials 24, 1466-1470.

Khademhosseini, A., Langer, R., Borenstein, J., Vacanti, J.P., 2006. Microscale technologies for tissue engineering and biology. Proceedings of the National Academy of Sciences of the United States of America 103, 2480-2487.

Kim, T.G., Park, T.G., 2006. Biomimicking extracellular matrix: Cell adhesive RGD peptide modified electrospun poly( D, L-lactic-Co-glycolic acid) nanofiber mesh. Tissue Engineering 12, 221-233.

Kisiday, J., Jin, M., Kurz, B., Hung, H., Semino, C., Zhang, S., Grodzinsky, A.J., 2002. Self-assembling peptide hydrogel fosters chondrocyte extracellular matrix production and cell division: Implications for cartilage tissue repair. Proceedings of the National Academy of Sciences of the United States of America 99, 9996-10001.

Knight, C.G., Morton, L.F., Peachey, A.R., Tuckwell, D.S., Farndale, R.W., Barnes, M.J., 2000. The collagen-binding A-domains of integrins alpha(1)beta(1) and alpha(2)beta(1) recognize the same specific amino acid sequence, GFOGER, in native (triple-helical) collagens. Journal of Biological Chemistry 275, 35-40.

Knudson, C.B., Knudson, W., 2001. Cartilage proteoglycans. Seminars in Cell \& Developmental Biology 12, 69-78. 
Kronenberg, H.M., 2003. Developmental regulation of the growth plate. Nature 423, 332-336.

Kuhnt, T., Herrmann, A., Benczedi, D., Foster, E.J., Weder, C., 2015. Functionalized cellulose nanocrystals as nanocarriers for sustained fragrance release. Polymer Chemistry 6, 6553-6562.

Kumari, A., Yadav, S.K., Yadav, S.C., 2010. Biodegradable polymeric nanoparticles based drug delivery systems. Colloids and Surfaces B-Biointerfaces 75, 1-18.

Laflamme, M.A., Murry, C.E., 2011. Heart regeneration. Nature 473, 326-335.

Langer, R., Vacanti, J.P., 1993. Tissue Engineering. Science 260, 920-926.

Lau, T.T., Wang, D.-A., 2013. Bioresponsive hydrogel scaffolding systems for 3D constructions in tissue engineering and regenerative medicine. Nanomedicine 8, 655-668.

Lebaron, R.G., Athanasiou, K.A., 2000. Extracellular matrix cell adhesion peptides: Functional applications in orthopedic materials. Tissue Engineering 6, 85-103.

Lee, J.-Y., Choo, J.-E., Choi, Y.-S., Lee, K.-Y., Min, D.-S., Pi, S.-H., Seol, Y.-J., Lee, S.-J., Jo, I.-H., Chung, C.P., Park, Y.-J., 2007. Characterization of the surface immobilized synthetic heparin binding domain derived from human fibroblast growth factor- 2 and its effect on osteoblast differentiation. Journal of Biomedical Materials Research Part A 83A, 970-979.

Lee, K., Silva, E.A., Mooney, D.J., 2011. Growth factor delivery-based tissue engineering: general approaches and a review of recent developments. Journal of the Royal Society Interface 8, 153170.

Levingstone, T.J., Matsiko, A., Dickson, G.R., O’Brien, F.J., Gleeson, J.P., 2014. A biomimetic multilayered collagen-based scaffold for osteochondral repair. Acta Biomaterialia 10, 1996-2004.

Levingstone, T.J., Ramesh, A., Brady, R.T., Brama, P.A.J., Kearney, C., Gleeson, J.P., O'Brien, F.J., 2016. Cell-free multi-layered collagen-based scaffolds demonstrate layer specific regeneration of functional osteochondral tissue in caprine joints. Biomaterials 87, 69-81.

Li, H., Cooper-White, J.J., 2014. Changing ligand number and type within nanocylindrical domains through kinetically constrained self-assembly - impacts of ligand 'redundancy' on human mesenchymal stem cell adhesion and morphology. Biomaterials Science 2, 1693-1705.

Li, H., Frith, J., Cooper-White, J.J., 2014. Modulation of Stem Cell Adhesion and Morphology via Facile Control over Surface Presentation of Cell Adhesion Molecules. Biomacromolecules 15, 43-52.

Li, J.J., Kim, K., Roohani-Esfahani, S.I., Guo, J., Kaplan, D.L., Zreiqat, H., 2015. A biphasic scaffold based on silk and bioactive ceramic with stratified properties for osteochondral tissue regeneration. Journal of Materials Chemistry B 3, 5361-5376.

Liao, I.C., Moutos, F.T., Estes, B.T., Zhao, X., Guilak, F., 2013. Composite Three-Dimensional Woven Scaffolds with Interpenetrating Network Hydrogels to Create Functional Synthetic Articular Cartilage. Advanced Functional Materials 23, 5833-5839.

Liu, X., Jin, X., Ma, P.X., 2011. Nanofibrous hollow microspheres self-assembled from star-shaped polymers as injectable cell carriers for knee repair. Nature Materials 10, 398-406.

Liverani, L., Roether, J.A., Nooeaid, P., Trombetta, M., Schubert, D.W., Boccaccini, A.R., 2012. Simple fabrication technique for multilayered stratified composite scaffolds suitable for interface tissue engineering. Materials Science and Engineering: A 557, 54-58.

Macconaill, M.A., 1951. The movements of bones and joints .4. The mechanical structure of articulating cartilage. Journal of Bone and Joint Surgery-British Volume 33, 251-257.

Makris, E.A., Gomoll, A.H., Malizos, K.N., Hu, J.C., Athanasiou, K.A., 2015. Repair and tissue engineering techniques for articular cartilage. Nature Reviews Rheumatology 11, 21-34.

Man, Z., Yin, L., Shao, Z., Zhang, X., Hu, X., Zhu, J., Dai, L., Huang, H., Yuan, L., Zhou, C., Chen, H., Ao, $Y ., 2014$. The effects of co-delivery of BMSC-affinity peptide and rhTGF- $\beta 1$ from coaxial electrospun scaffolds on chondrogenic differentiation. Biomaterials 35, 5250-5260.

Maroudas, A., Muir, H., Wingham, J., 1969. Correlation of fixed negative charge with glycosaminoglycan content of human articular cartilage. Biochimica Et Biophysica Acta 177, $492-$ 500. 
Mathieu, P.S., Loboa, E.G., 2012. Cytoskeletal and Focal Adhesion Influences on Mesenchymal Stem Cell Shape, Mechanical Properties, and Differentiation Down Osteogenic, Adipogenic, and Chondrogenic Pathways. Tissue Engineering Part B-Reviews 18, 436-444.

Meng, Q.Y., Man, Z.T., Dai, L.H., Huang, H.J., Zhang, X., Hu, X.Q., Shao, Z.X., Zhu, J.X., Zhang, J.Y., Fu, X., Duan, X.N., Ao, Y.F., 2015. A composite scaffold of MSC affinity peptide-modified demineralized bone matrix particles and chitosan hydrogel for cartilage regeneration. Scientific Reports 5.

Messner, K., Gillquist, J., 1996. Cartilage repair: A critical review. Acta Orthopaedica 67, 523-529.

Mhanna, R., Oeztuerk, E., Vallmajo-Martin, Q., Millan, C., Mueller, M., Zenobi-Wong, M., 2014. GFOGER-Modified MMP-Sensitive Polyethylene Glycol Hydrogels Induce Chondrogenic Differentiation of Human Mesenchymal Stem Cells. Tissue Engineering Part A 20, 1165-1174.

Minas, T., Peterson, L., 2000. Autologous chondrocyte transplantation. Operative Techniques in Sports Medicine 8, 144-157.

Mithoefer, K., McAdams, T., Williams, R.J., Kreuz, P.C., Mandelbaum, B.R., 2009. Clinical Efficacy of the Microfracture Technique for Articular Cartilage Repair in the Knee An Evidence-Based Systematic Analysis. American Journal of Sports Medicine 37, 2053-2063.

Moeinzadeh, S., Pajoum Shariati, S.R., Jabbari, E., 2016. Comparative effect of physicomechanical and biomolecular cues on zone-specific chondrogenic differentiation of mesenchymal stem cells. Biomaterials 92, 57-70.

Mohan, N., Dormer, N.H., Caldwell, K.L., Key, V.H., Berkland, C.J., Detamore, M.S., 2011. Continuous Gradients of Material Composition and Growth Factors for Effective Regeneration of the Osteochondral Interface. Tissue Engineering Part A 17, 2845-2855.

Moore, N.M., Lin, N.J., Gallant, N.D., Becker, M.L., 2011. Synergistic enhancement of human bone marrow stromal cell proliferation and osteogenic differentiation on BMP-2-derived and RGD peptide concentration gradients. Acta Biomaterialia 7, 2091-2100.

Moseley, J.B., Anderson, A.F., Browne, J.E., Mandelbaum, B.R., Micheli, L.J., Fu, F., Erggelet, C., 2010. Long-Term Durability of Autologous Chondrocyte Implantation A Multicenter, Observational Study in US Patients. American Journal of Sports Medicine 38, 238-246.

Moutos, F.T., Freed, L.E., Guilak, F., 2007. A biomimetic three-dimensional woven composite scaffold for functional tissue engineering of cartilage. Nature Materials 6, 162-167.

Mow, V.C., Holmes, M.H., Lai, W.M., 1984. Fluid transport and mechanical-properties of articularcartilage - A review. Journal of Biomechanics 17, 377-394.

Mrksich, M., 2009. Using self-assembled monolayers to model the extracellular matrix. Acta Biomaterialia 5, 832-841.

Nguyen, L.H., Kudva, A.K., Saxena, N.S., Roy, K., 2011. Engineering articular cartilage with spatiallyvarying matrix composition and mechanical properties from a single stem cell population using a multi-layered hydrogel. Biomaterials 32, 6946-6952.

Niemeyer, P., Porichis, S., Steinwachs, M., Erggelet, C., Kreuz, P.C., Schmal, H., Uhl, M., Ghanem, N., Sudkamp, N.P., Salzmann, G., 2014. Long-term Outcomes After First-Generation Autologous Chondrocyte Implantation for Cartilage Defects of the Knee. American Journal of Sports Medicine 42, 150-157.

Nooeaid, P., Roether, J.A., Weber, E., Schubert, D.W., Boccaccini, A.R., 2014. Technologies for Multilayered Scaffolds Suitable for Interface Tissue Engineering. Advanced Engineering Materials 16, 319-327.

Nooeaid, P., Salih, V., Beier, J.P., Boccaccini, A.R., 2012. Osteochondral tissue engineering: scaffolds, stem cells and applications. Journal of Cellular and Molecular Medicine 16, 2247-2270.

Olszta, M.J., Cheng, X.G., Jee, S.S., Kumar, R., Kim, Y.Y., Kaufman, M.J., Douglas, E.P., Gower, L.B., 2007. Bone structure and formation: A new perspective. Materials Science \& Engineering R-Reports 58, 77-116.

Ott, H.C., Clippinger, B., Conrad, C., Schuetz, C., Pomerantseva, I., Ikonomou, L., Kotton, D., Vacanti, J.P., 2010. Regeneration and orthotopic transplantation of a bioartificial lung. Nature Medicine 16, 927-U131. 
Park, J.S., Chu, J.S., Tsou, A.D., Diop, R., Tang, Z., Wang, A., Li, S., 2011. The effect of matrix stiffness on the differentiation of mesenchymal stem cells in response to TGF-beta. Biomaterials 32, 39213930.

Park, J.S., Na, K., Woo, D.G., Yang, H.N., Park, K.-H., 2009. Determination of dual delivery for stem cell differentiation using dexamethasone and TGF- $\beta 3$ in/on polymeric microspheres. Biomaterials 30 , 4796-4805.

Petros, R.A., DeSimone, J.M., 2010. Strategies in the design of nanoparticles for therapeutic applications. Nature Reviews Drug Discovery 9, 615-627.

Poole, A.R., Pidoux, I., Reiner, A., Rosenberg, L., 1982. An immunoelectron microscope study of the organization of proteoglycan monomer, link protein, and collagen in the matrix of articularcartilage. Journal of Cell Biology 93, 921-937.

Poole, C.A., 1997. Review. Articular cartilage chondrons: form, function and failure. Journal of Anatomy 191, 1-13.

Poole, C.A., Flint, M.H., Beaumont, B.W., 1987. Chondrons in cartilage - ultrastructural analysis of the pericellular microenvironment in adult human articular cartilages. Journal of Orthopaedic Research $5,509-522$.

Prittinen, J., Jiang, Y., Ylarinne, J.H., Pakkanen, T.A., Lammi, M.J., Qu, C., 2014. Chondrocyte behavior on nanostructured micropillar polypropylene and polystyrene surfaces. Materials Science \& Engineering C-Materials for Biological Applications 43, 424-431.

Prowse, A.B.J., Chong, F., Gray, P.P., Munro, T.P., 2011. Stem cell integrins: Implications for ex-vivo culture and cellular therapies. Stem Cell Research 6, 1-12.

Rahmany, M.B., Van Dyke, M., 2013. Biomimetic approaches to modulate cellular adhesion in biomaterials: A review. Acta Biomaterialia 9, 5431-5437.

Raynor, J.E., Petrie, T.A., Garcia, A.J., Collard, D.M., 2007. Controlling cell adhesion to titanium: Functionalization of poly oligo(ethylene glycol)methacrylate brushes with cell-adhesive peptides. Advanced Materials 19, 1724-+.

Redler, I., Mow, v.C., Zimny, M.I., Mansell, J., 1975. The Ultrastructure and Biomechanical Significance of the Tidemark of Articular Cartilage. Clinical Orthopaedics and Related Research 112, 357-362.

Rodrigues, M.T., Lee, S.J., Gomes, M.E., Reis, R.L., Atala, A., Yoo, J.J., 2012. Bilayered constructs aimed at osteochondral strategies: The influence of medium supplements in the osteogenic and chondrogenic differentiation of amniotic fluid-derived stem cells. Acta Biomaterialia 8, 2795-2806.

Rowlands, A.S., George, P.A., Cooper-White, J.J., 2008. Directing osteogenic and myogenic differentiation of MSCs: interplay of stiffness and adhesive ligand presentation. American Journal of Physiology-Cell Physiology 295, C1037-C1044.

Salazar, R.B., Shovsky, A., Schoenherr, H., Vancso, G.J., 2006. Dip-pen nanolithography on (bio)reactive monolayer and block-copolymer platforms: Deposition of lines of single macromolecules. Small 2, 1274-1282.

Salinas, C.N., Anseth, K.S., 2008. The enhancement of chondrogenic differentiation of human mesenchymal stem cells by enzymatically regulated RGD functionalities. Biomaterials 29, 23702377.

Salinas, C.N., Anseth, K.S., 2009. Decorin moieties tethered into PEG networks induce chondrogenesis of human mesenchymal stem cells. Journal of Biomedical Materials Research Part A 90A, 456-464.

Schuh, E., Kramer, J., Rohwedel, J., Notbohm, H., Müller, R., Gutsmann, T., Rotter, N., 2009. Effect of Matrix Elasticity on the Maintenance of the Chondrogenic Phenotype. Tissue Engineering Part A $16,1281-1290$.

Schumacher, B.L., Block, J.A., Schmid, T.M., Aydelotte, M.B., Kuettner, K.E., 1994. A novel proteoglycan synthesized and secreted by chondrocytes of the superficial zone of articular-cartilage. Archives of Biochemistry and Biophysics 311, 144-152.

Shah, R.N., Shah, N.A., Lim, M.M.D.R., Hsieh, C., Nuber, G., Stupp, S.I., 2010. Supramolecular design of self-assembling nanofibers for cartilage regeneration. Proceedings of the National Academy of Sciences of the United States of America 107, 3293-3298. 
Shin, H., Jo, S., Mikos, A.G., 2003. Biomimetic materials for tissue engineering. Biomaterials 24, $4353-$ 4364.

Sinthuvanich, C., Haines-Butterick, L.A., Nagy, K.J., Schneider, J.P., 2012. Iterative design of peptidebased hydrogels and the effect of network electrostatics on primary chondrocyte behavior. Biomaterials 33, 7478-7488.

Slaughter, B.V., Khurshid, S.S., Fisher, O.Z., Khademhosseini, A., Peppas, N.A., 2009. Hydrogels in Regenerative Medicine. Advanced Materials 21, 3307-3329.

Smith, G.D., Knutsen, G., Richardson, J.B., 2005. A clinical review of cartilage repair techniques. Journal of Bone and Joint Surgery-British Volume 87B, 445-449.

Spiller, K.L., Maher, S.A., Lowman, A.M., 2011. Hydrogels for the Repair of Articular Cartilage Defects. Tissue Engineering Part B-Reviews 17, 281-299.

Sreejalekshmi, K.G., Nair, P.D., 2011. Biomimeticity in tissue engineering scaffolds through synthetic peptide modifications-Altering chemistry for enhanced biological response. Journal of Biomedical Materials Research Part A 96A, 477-491.

Staatz, W.D., Fok, K.F., Zutter, M.M., Adams, S.P., Rodriguez, B.A., Santoro, S.A., 1991. IDENTIFICATION OF A TETRAPEPTIDE RECOGNITION SEQUENCE FOR THE ALPHA-2-BETA-1-INTEGRIN IN COLLAGEN. Journal of Biological Chemistry 266, 7363-7367.

Steadman, J.R., Briggs, K.K., Rodrigo, J.J., Kocher, M.S., Gill, T.J., Rodkey, W.G., 2003. Outcomes of microfracture for traumatic chondral defects of the knee: Average 11-year follow-up. Arthroscopythe Journal of Arthroscopic and Related Surgery 19, 477-484.

Steadman, J.R., Rodkey, W.G., Briggs, K.K., Rodrigo, J.J., 1998. The microfracture procedure: Rationale, technique, and clinical observations for treatment of articular cartilage defects. Journal of Sports Traumatology and Related Research 20, 61-70.

Steele, J.A.M., McCullen, S.D., Callanan, A., Autefage, H., Accardi, M.A., Dini, D., Stevens, M.M., 2014. Combinatorial scaffold morphologies for zonal articular cartilage engineering. Acta Biomaterialia 10, 2065-2075.

Stevens, M.M., George, J.H., 2005. Exploring and engineering the cell surface interface. Science 310, $1135-1138$.

Takebe, T., Sekine, K., Enomura, M., Koike, H., Kimura, M., Ogaeri, T., Zhang, R.R., Ueno, Y., Zheng, Y.W., Koike, N., Aoyama, S., Adachi, Y., Taniguchi, H., 2013. Vascularized and functional human liver from an iPSC-derived organ bud transplant. Nature 499, 481-+.

Tan, G.K., Dinnes, D.L.M., Myers, P.T., Cooper-White, J.J., 2011. Effects of biomimetic surfaces and oxygen tension on redifferentiation of passaged human fibrochondrocytes in $2 \mathrm{D}$ and $3 \mathrm{D}$ cultures. Biomaterials 32, 5600-5614.

Tan, H., Chu, C.R., Payne, K.A., Marra, K.G., 2009. Injectable in situ forming biodegradable chitosanhyaluronic acid based hydrogels for cartilage tissue engineering. Biomaterials 30, 2499-2506.

Temenoff, J.S., Mikos, A.G., 2000. Review: tissue engineering for regeneration of articular cartilage. Biomaterials 21, 431-440.

Toh, W.S., Lim, T.C., Kurisawa, M., Spector, M., 2012. Modulation of mesenchymal stem cell chondrogenesis in a tunable hyaluronic acid hydrogel microenvironment. Biomaterials 33, 38353845 .

Trappmann, B., Gautrot, J.E., Connelly, J.T., Strange, D.G.T., Li, Y., Oyen, M.L., Cohen Stuart, M.A., Boehm, H., Li, B., Vogel, V., Spatz, J.P., Watt, F.M., Huck, W.T.S., 2012. Extracellular-matrix tethering regulates stem-cell fate. Nat Mater 11, 642-649.

Unadkat, H.V., Hulsman, M., Cornelissen, K., Papenburg, B.J., Truckenmuller, R.K., Post, G.F., Uetz, M., Reinders, M.J.T., Stamatialis, D., van Blitterswijk, C.A., de Boer, J., 2011. An algorithm-based topographical biomaterials library to instruct cell fate. Proceedings of the National Academy of Sciences of the United States of America 108, 16565-16570.

Ustun, S., Tombuloglu, A., Kilinc, M., Guler, M.O., Tekinay, A.B., 2013. Growth and Differentiation of Prechondrogenic Cells on Bioactive Self-Assembled Peptide Nanofibers. Biomacromolecules 14, 17-26. 
Vacanti, J.P., 1988. BEYOND TRANSPLANTATION - 3RD ANNUAL MIXTER,SAMUEL,JASON, LECTURE. Archives of Surgery 123, 545-549.

Vaquette, C., Cooper-White, J., 2013. A simple method for fabricating 3-D multilayered composite scaffolds. Acta Biomaterialia 9, 4599-4608.

Venn, M., Maroudas, A., 1977. Chemical composition and swelling of normal and osteoarthrotic femoral-head cartilage .1. Chemical composition. Annals of the Rheumatic Diseases 36, 121-129.

Viola, J., Lal, B., Grad, O., 2003. The Emergence of Tissue Engineering as a Research Field. NSF, Arlington, $V A$.

Visser, J., Melchels, F.P.W., Jeon, J.E., van Bussel, E.M., Kimpton, L.S., Byrne, H.M., Dhert, W.J.A., Dalton, P.D., Hutmacher, D.W., Malda, J., 2015. Reinforcement of hydrogels using threedimensionally printed microfibres. Nat Commun 6.

Vogt, S., Imhoff, A., 2006. Injuries to the Articular Cartilage. European Journal of Trauma 32, 325-331.

Wang, Y.Z., Blasioli, D.J., Kim, H.J., Kim, H.S., Kaplan, D.L., 2006. Cartilage tissue engineering with silk scaffolds and human articular chondrocytes. Biomaterials 27, 4434-4442.

Watari, S., Hayashi, K., Wood, J.A., Russell, P., Nealey, P.F., Murphy, C.J., Genetos, D.C., 2012. Modulation of osteogenic differentiation in hMSCs cells by submicron topographically-patterned ridges and grooves. Biomaterials 33, 128-136.

Watt, F.M., Huck, W.T.S., 2013. Role of the extracellular matrix in regulating stem cell fate. Nature Reviews Molecular Cell Biology 14, 467-473.

Wen, J.H., Vincent, L.G., Fuhrmann, A., Choi, Y.S., Hribar, K.C., Taylor-Weiner, H., Chen, S.C., Engler, A.J., 2014. Interplay of matrix stiffness and protein tethering in stem cell differentiation. Nature Materials 13, 979-987.

Williams, G.M., Klisch, S.M., Sah, R.L., 2008. Bioengineering cartilage growth, maturation, and form. Pediatric Research 63, 527-534.

Wu, J.P., Kirk, T.B., Zheng, M.H., 2008. Study of the collagen structure in the superficial zone and physiological state of articular cartilage using a 3D confocal imaging technique. Journal of orthopaedic surgery and research 3, 29-29.

Wu, Y.-N., Law, J.B.K., He, A.Y., Low, H.Y., Hui, J.H.P., Lim, C.T., Yang, Z., Lee, E.H., 2014. Substrate topography determines the fate of chondrogenesis from human mesenchymal stem cells resulting in specific cartilage phenotype formation. Nanomedicine: Nanotechnology, Biology and Medicine 10, 1507-1516.

Yao, X., Peng, R., Ding, J., 2013. Cell-Material Interactions Revealed Via Material Techniques of Surface Patterning. Advanced Materials 25, 5257-5286.

Yim, E.K.F., Darling, E.M., Kulangara, K., Guilak, F., Leong, K.W., 2010. Nanotopography-induced changes in focal adhesions, cytoskeletal organization, and mechanical properties of human mesenchymal stem cells. Biomaterials 31, 1299-1306.

Youn, I., Choi, J.B., Cao, L., Setton, L.A., Guilak, F., 2006. Zonal variations in the three-dimensional morphology of the chondron measured in situ using confocal microscopy. Osteoarthritis and Cartilage 14, 889-897.

Yourek, G., Hussain, M.A., Mao, J.J., 2007. Cytoskeletal changes of mesenchymal stem cells during differentiation. Asaio Journal 53, 219-228.

Yousefi, A.-M., Hoque, M.E., Prasad, R.G.S.V., Uth, N., 2015. Current strategies in multiphasic scaffold design for osteochondral tissue engineering: A review. Journal of Biomedical Materials Research Part A 103, 2460-2481.

Zhang, S.G., 2003. Fabrication of novel biomaterials through molecular self-assembly. Nature Biotechnology 21, 1171-1178.

Zhao, L., Liu, L., Wu, Z., Zhang, Y., Chu, P.K., 2012. Effects of micropitted/nanotubular titania topographies on bone mesenchymal stem cell osteogenic differentiation. Biomaterials 33, 26292641. 
Zhu, Y., Wu, H., Sun, S., Zhou, T., Wu, J., Wan, Y., 2014. Designed composites for mimicking compressive mechanical properties of articular cartilage matrix. Journal of the Mechanical Behavior of Biomedical Materials 36, 32-46.

Table of Content (TOC)

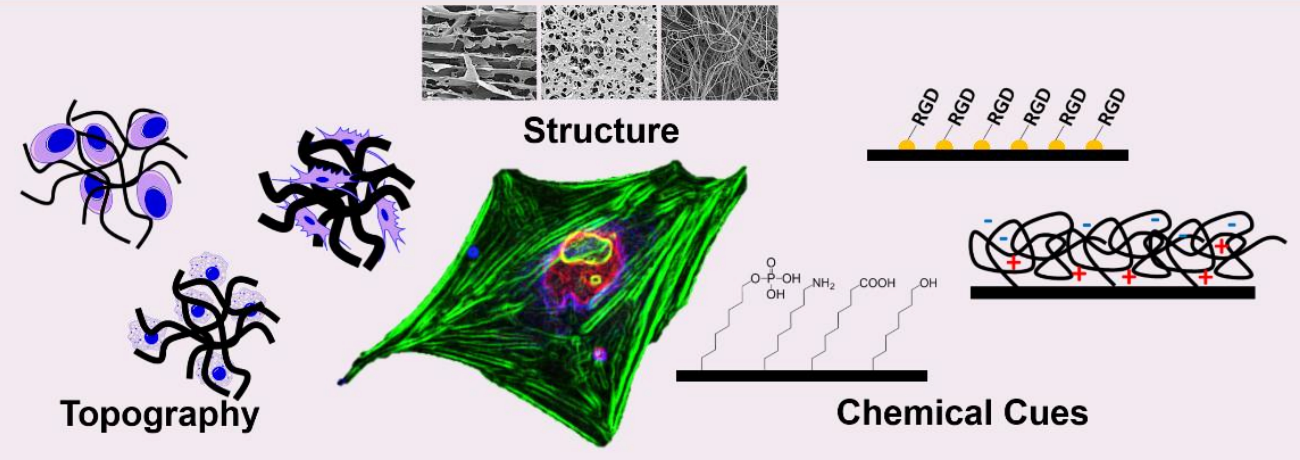

0000

Mechanical Cues 